\title{
¿Upscale Impact of Mesoscale Disturbances of Tropical Convection on 2-Day Waves
}

\author{
QIU YANG \\ Center for Prototype Climate Modeling, New York University Abu Dhabi, Saadiyat Island, Abu Dhabi, United Arab Emirates
}

\begin{abstract}
ANDREW J. MAJDA
Department of Mathematics, and Center for Atmosphere Ocean Science, Courant Institute of Mathematical Sciences, New York University, New York, New York, and Center for Prototype Climate Modeling, New York University Abu Dhabi, Saadiyat Island, Abu Dhabi, United Arab Emirates
\end{abstract}

(Manuscript received 14 February 2018, in final form 19 September 2018)

\begin{abstract}
Westward-propagating 2-day waves with embedded mesoscale disturbances contribute a large portion of synoptic variability of tropical convection over the western Pacific. It is of crucial importance to assess the upscale impact on 2-day waves of these mesoscale disturbances that propagate at various tilt angles. Also, it will be informative to consider the upscale impact on both symmetric and asymmetric 2-day waves in terms of convection, morphology of circulation, and tropical cyclogenesis. A simple multiscale asymptotic model is used to simulate the two-scale structure of 2-day waves. The synoptic-scale circulation response is driven by westward-propagating mean heating and eddy transfer of momentum and temperature. The latter is interpreted as the upscale impact of mesoscale fluctuations. The upscale impact of mesoscale disturbances that propagate at a tilt angle between $315^{\circ}$ and $45^{\circ}$ induces low-level negative potential temperature anomalies and westerly inflow. Shallow congestus convection triggered in a moist environment at the leading edge of the 2-day waves supports the westward propagation. For asymmetric 2-day waves in the Northern Hemisphere, the upscale impact of mesoscale disturbances propagating at a tilt angle between $315^{\circ}$ and $0^{\circ}$ induces lowertropospheric cyclonic flows and negative pressure perturbation. This provides a new mechanism to precondition tropical cyclogenesis. A comparison of the upscale impact on symmetric westward-propagating 2-day waves and eastward-propagating convectively coupled Kelvin waves shows that their tilt angle ranges with favorable conditions for convection and enhanced inflow are simply opposite.
\end{abstract}

\section{Introduction}

Superclusters of cloudiness over several thousand kilometers frequently observed in the tropics have a dramatic impact on local weather and global climate as a result of large amounts of rainfall (Nakazawa 1988; Mapes and Houze 1993). It is now well understood that these superclusters are organized by the coupling between equatorially trapped waves and tropical convection (Matsuno 1966; Takayabu 1994a; Wheeler et al. 2000; Roundy and Frank 2004; Yang et al. 2007a,b,c; Kiladis et al. 2009), such as eastward-propagating convectively coupled Kelvin waves (CCKWs) (Straub and Kiladis 2002). The 2-day waves are key components of westward-propagating superclusters,

¿ Denotes content that is immediately available upon publication as open access.

Corresponding author: Qiu Yang, yangq@cims.nyu.edu which prevail over the western Pacific (WP) (Takayabu 1994b; Takayabu et al. 1996), especially during the active phase of the Madden-Julian oscillation (MJO) (Schrage et al. 2001; Clayson et al. 2002). Observational studies have been based on satellite infrared data and in situ surface measurements from the Tropical Ocean and Global Atmosphere Coupled Ocean-Atmosphere Response Experiment (TOGA COARE) (Chen et al. 1996; Takayabu et al. 1996; Chen and Houze 1997; Haertel and Johnson 1998; Clayson et al. 2002). Takayabu (1994b) recognized that 2-day waves have $n=1$ westward-propagating inertiogravity (WIG) wave properties. Chen and Houze (1997) called the spatially selective behavior of the large convective systems diurnal dancing and concluded that the 2-day period is determined by the boundary layer recovery phase. Stechmann and Majda (2009) explained the preferred westward propagation of 2-day waves in terms of the effects of wind shear and gravity waves that create more favorable conditions on one side of convective systems. 


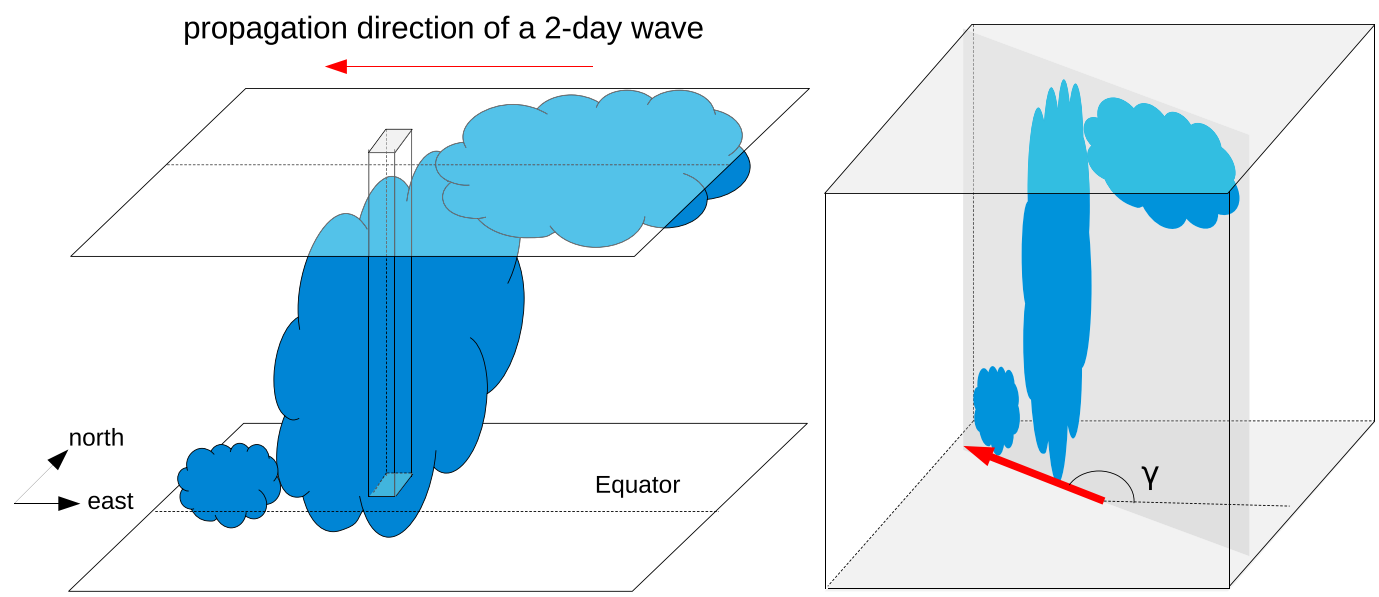

FIG. 1. Conceptual diagram for a 2-day wave with embedded mesoscale disturbances. (left) An westward-moving 2-day wave (blue) on the synoptic scale, where the rectangular cuboid denotes a mesoscale domain. (right) An MCS propagating at a tilt angle $\gamma$ in the mesoscale domain (zoomed-in view of the rectangular cuboid in the left panel).

Multiscale organization of tropical convection sheds new light on understanding 2-day waves. Chen et al. (1996) observed that the 2-day disturbances extensively contain cloud clusters, the dominant rainfall producer in the tropics (Tao and Moncrieff 2009), most of which moved westward. For cluster-supercluster interactions, Yang and Majda (2018) accessed the upscale impact of embedded mesoscale tropical convection on CCKWs based on a simple multiscale model. Early studies about scale interactions of atmospheric flows included wavemean flow interactions (Andrews and McIntyre 1976a,b, 1978a,b,c). Majda (2007) showed that nonlinear interactions across scales that drive the waves include eddy flux divergences of momentum and temperature from the smaller-scale systems as well as large-scale effects. The multiscale structure of 2-day waves with embedded mesoscale disturbances considered here are illustrated in the conceptual diagram in Fig. 1.

Besides the symmetric $n=1$ WIGs, recent studies based on satellite-observed outgoing longwave radiation (OLR) show the existence of asymmetric $n=2$ WIGs with significant spectral signals close to the 2-day period (Wheeler and Kiladis 1999; Wheeler et al. 2000; Kiladis et al. 2009). Kiladis et al. (2009) showed that heavy rainfall identified by the annual mean variance of brightness temperature filtered for the WIG bands occurs widely in equatorial regions, including the WP from $10^{\circ} \mathrm{S}$ to $10^{\circ} \mathrm{N}$. Roundy and Frank (2004) showed that spectral signals of WIGs are more significant in the Northern Hemisphere $(\mathrm{NH})$ than the Southern Hemisphere $(\mathrm{SH})$. This suggests a connection between asymmetric 2-day waves and tropical cyclogenesis in the NH. Frank and Roundy (2006) concluded that tropical cyclone formation is closely related to enhanced wave activity. T. J. Dunkerton and his collaborators studied tropical cyclogenesis in a tropical wave critical layer, particularly easterly waves, focusing on flow kinematics and dynamics, moist thermodynamics, and wave-vortex interactions (Dunkerton et al. 2009; Wang et al. 2010; Lussier et al. 2015). It is necessary to investigate how 2-day waves with embedded mesoscale disturbances influence tropical cyclogenesis.

Because of their coarse resolution, most GCMs cannot explicitly resolve MCSs and have to rely on cumulus parameterization. Inadequate treatment of MCSs and their upscale impact on the large-scale circulation may explain systematical precipitation bias in GCMs (Dai 2006; Lin 2007; Li and Xie 2014; Woelfle et al. 2018). As an important component of high-frequency variability within the large-scale convective envelope of MJOs (Zhang 2005), 2-day waves that include the effect of mesoscale disturbances may improve the treatment of MJOs. Improved WIG simulations by Khouider and Majda (2008a) are based on the multicloud model parameterization (Khouider and Majda 2006c,a,b, 2008a,b; Khouider et al. 2010, 2011). Moncrieff et al.'s (2017) new approach for parameterizing upscale effects of organized tropical convection showed promising improvement in representing large-scale precipitation and tropical wave modes in GCMs.

The goals of this paper include four aspects: First, a simple multiscale framework models the synoptic-scale 2-day waves with embedded mesoscale disturbances; second, the upscale impact of mesoscale disturbances that propagate at various tilt angles on 2-day waves is assessed in terms of favorable conditions for convection, circulation morphology, and tropical cyclogenesis; third, the upscale impact of mesoscale disturbances on asymmetric 2-day waves that propagate off the equator in the 
$\mathrm{NH}$ is investigated; and Last, the upscale impact of mesoscale disturbances on westward-propagating 2-day waves versus eastward-propagating CCKWs is compared.

Early studies of the multiscale formalism in atmospheric sciences include quasi-biennial oscillations (Plumb and Bell 1982; Lindzen 1987; Takahashi and Holton 1991). The mesoscale equatorial synoptic dynamics (MESD) model derived by Majda (2007) for studying cluster-supercluster interactions is used here. Inspired by the observed selfsimilarity of clusters, superclusters, and intraseasonal oscillations, multiscale models based on multiscale asymptotic methods (Majda and Klein 2003; Majda 2007) have studied complex multiple-spatiotemporal-scale interactions of tropical convection ranging from mesoscale to synoptic scale to intraseasonal/planetary scale (Majda and Biello 2004; Biello and Majda 2005, 2006, 2010; Yang and Majda 2014; Majda and Yang 2016; Yang et al. 2017). The MESD model highlights eddy transfer of momentum and temperature in driving synoptic-scale circulation, which concerns the upscale impact of mesoscale fluctuations. Yang and Majda (2017) used the two-dimensional version of the MESD model to simulate eastward-propagating synoptic-scale superclusters with embedded westward-propagating mesoscale disturbances. They successfully reproduced key features of convective systems with a front-to-rear tilt that compared well with results from a cloud-resolving model (Grabowski and Moncrieff 2001). Yang and Majda (2018) used the three-dimensional version of the MESD to study the upscale impact on CCKWs of mesoscale disturbances propagating at various tilt angles and speeds. In contrast to the eastward-propagating CCKWs in Yang and Majda (2018), herein the MESD model is configured to represent 2-day waves with a westward-propagating convective envelope and embedded mesoscale disturbances propagating at various tilt angles. Both symmetric (along the equator) and asymmetric (off the equator) 2-day waves are examined.

Several crucial results that have been obtained pertain to a moist environment by comparing the mean heatingdriven 2-day waves with the superimposed flow field anomalies induced by eddy transfer of momentum and temperature. First, explicit expressions for eddy transfer of momentum and temperature from mesoscale fluctuations are obtained. Second, for symmetric 2-day waves, the upscale impact of mesoscale disturbances propagating at the tilt-angle ranges of $315^{\circ}-0^{\circ}$ and $0^{\circ}-45^{\circ}$ (close to the eastward direction) induces low-level negative potential temperature anomalies to the west around $2-3-\mathrm{km}$ altitude, providing favorable conditions to trigger shallow congestus convection at the leading edge and explaining the favored westward propagation rather than eastward propagation. Additional westerly inflow induced by this upscale impact around $5 \mathrm{~km}$ feeds moisture toward the convective envelope to generate convective available potential energy (CAPE). Third, for asymmetric 2-day waves, the upscale impact of mesoscale disturbances propagating at the tilt-angle range of $315^{\circ}-0^{\circ}$ induces east-southward jets accompanied by cyclonic flows and negative pressure perturbation at equatorial latitudes of the $\mathrm{NH}$, a possible precondition for tropical cyclogenesis. Last, a comparison between symmetric westward-propagating 2-day waves and eastward-propagating CCKWs shows the anticipated result that their tilt angle ranges with favorable conditions for convection and enhanced inflow are simply opposite in direction.

The results of this paper is presented as follows. Section 2 summarizes properties of the MESD model and explicit expressions of eddy transfer of momentum and temperature (Yang and Majda 2018). Section 3 discusses the synoptic-scale circulation response to westwardpropagating mean heating and the upscale impact of embedded mesoscale disturbances propagating at various tilt angles. Section 4 considers asymmetric 2-day waves where the convective envelope propagates westward off the equator in the $\mathrm{NH}$. Section 5 compares the upscale impact of mesoscale disturbances on westward-propagating 2-day waves versus eastward-propagating CCKWs. The paper concludes with a discussion in section 6 .

\section{Properties of the MESD model}

The MESD model originally derived by Majda (2007) is based on multiscale asymptotic methods. The derivation starts from the primitive equations, undertakes asymptotic expansions with respect to the small Froude number $(\varepsilon=0.1)$, and defines a multiscale framework that includes the mesoscale and synoptic scales. The essential physical intuition behind the derivation includes the multiscale organization of tropical convection and self-similarity properties across scales (Mapes et al. 2006; Majda 2007). The application of its two-dimensional and three-dimensional versions for CCKWs validates the appropriateness of the MESD model to investigate clustersupercluster interactions (Yang and Majda 2017, 2018). The MESD model consists of two groups of equations: one governs synoptic-scale dynamics and the other mesoscale dynamics. As for the scale analysis, the synoptic space and time scale are $1500 \mathrm{~km}$ and $8.3 \mathrm{~h}$, respectively-10 times those on the mesoscale ( $150 \mathrm{~km}$ and $50 \mathrm{~min}$, respectively). Horizontal velocity on the synoptic- and mesoscale share the same scaling of $5 \mathrm{~m} \mathrm{~s}^{-1}$, while vertical velocity on the mesoscale has scaling of $1.6 \times 10^{-1} \mathrm{~m} \mathrm{~s}^{-1}-10$ times that on the synoptic scale $\left(1.6 \times 10^{-2} \mathrm{~m} \mathrm{~s}^{-1}\right)$. Potential temperature anomalies share the same $3.3-\mathrm{K}$ scaling, while diabatic heating on the mesoscale has a $100 \mathrm{Kday}^{-1}$ 
scaling -10 times that on the synoptic scale $\left(10 \mathrm{~K} \mathrm{day}^{-1}\right)$ (Robert 1982; Yanai and Johnson 1993). For simplicity, the Boussinesq approximation is used as a simple demonstration, although it should account for quasi-compressibility in reality.

The governing equations for synoptic-scale dynamics in dimensionless units are as follows:

$$
\begin{aligned}
U_{t}-Y V & =-P_{X}-d U-\left\langle\overline{w^{\prime} u^{\prime}}\right\rangle_{z}, \\
V_{t}+Y U & =-P_{Y}-d V-\left\langle\overline{{w^{\prime} v^{\prime}}_{z}},\right. \\
\Theta_{t}+W & \left.=-\overline{\left\langle w^{\prime} \theta^{\prime}\right.}\right\rangle_{z}+S^{\theta}, \\
P_{z} & =\Theta, \\
U_{X}+V_{Y}+W_{z} & =0,
\end{aligned}
$$

where $d=(1 \text { day })^{-1}$ is a damping coefficient for boundary layer turbulent drag and is set as a constant for simplicity; $S^{\theta}$ represents synoptic-scale diabatic heating from latent heat release. Such a thermally forced and momentumdamped model for a synoptic-scale circulation response is consistent with Haertel et al. (2008) in regard to 2-day waves. The notation bar and angle brackets in Eqs. (1a)(1c) denote mesoscale horizontal- and temporal-averaging operators, respectively. For an arbitrary function $f$,

$$
\begin{aligned}
\bar{f}(X, Y) & =\lim _{L \rightarrow \infty} \frac{1}{4 L^{2}} \int_{-L}^{L} \int_{-L}^{L} f(X, x, Y, y) d x d y, \\
\langle f\rangle(t) & =\lim _{T \rightarrow \infty} \frac{1}{2 T} \int_{-T}^{T} f(t, \tau) d \tau,
\end{aligned}
$$

where $L$ and $T$ denote the length of the mesoscale domain and the time interval. In the asymptotic limit, all mesoscale fluctuations of $f$ satisfy $\bar{f}=0$ and $\langle f\rangle=0$ by definition. According to the scaling analysis as mentioned before, those nonlinear advection terms appearing in the original governing equations are of order $\varepsilon$ on the synoptic scale and are therefore all ignored in accord with asymptotic assumptions (Majda 2007).

The governing equations for mesoscale dynamics in dimensionless units are

$$
\begin{array}{r}
u_{\tau}=-p_{x}, \\
v_{\tau}=-p_{y}, \\
\theta_{\tau}+w=s^{\theta}, \\
p_{z}=\theta, \\
u_{x}+v_{y}+w_{z}=0,
\end{array}
$$

where $s^{\theta}$ represents mesoscale diabatic heating from latent heat release. Unlike those in Eqs. (1a)-(1e), neither the Coriolis force nor the momentum damping terms appear in the mesoscale equations, since their magnitudes are on the order of $\varepsilon$ and are accordingly neglected as previously stated.

These two groups of equations not only describe the leading-order behavior of circulation response at each scale by a linear system, but they also highlight nonlinear eddy terms associated with cross-scale interactions. The synoptic-scale dynamics in Eqs. (1a)-(1e) responds to the Coriolis force on the $\beta$ plane, containing all dry equatorially trapped waves of Matsuno (1966) provided the momentum damping terms and eddy terms are ignored. The three eddy terms, $-\left\langle\overline{w^{\prime} u^{\prime}}\right\rangle_{z},-\left\langle\overline{w^{\prime} v^{\prime}}\right\rangle_{z},-\left\langle\overline{w^{\prime} \theta^{\prime}}\right\rangle_{z}$, and the mean heating $S^{\theta}$ drive synoptic-scale dynamics, representing the upscale impact of mesoscale fluctuations on synopticscale circulation through momentum and heat budget. The mesoscale dynamics in Eqs. (4a)-(4e), which consists of only gravity waves, is thermally driven by the mesoscale heating. The clear scale separation of synoptic- and mesoscale convective systems living on different spatiotemporal scales is the essential feature captured by multiscale models (Majda and Klein 2003). These multiscale asymptotic models are valid provided diabatic heating does not exceed their corresponding scales. According to the scale analysis with weak advection at order $\varepsilon$, the results are insensitive to these heating scales because of the linearity properties of governing equations on both scales. Notably, the original MESD model (Majda 2007) allows a background density vertical profile in the quasi-Boussinesq approximation, which would add an extra factor $e^{z / 2 H}$ in front of all variables for a vertically decaying background density $\rho(z)=\rho_{0} e^{-z / H}$ (Holton 1973; Andrews et al. 1987). Correspondingly, both eddy momentum flux $\overline{w^{\prime} u^{\prime}}$ (Fig. 4a) and eddy heat flux $\overline{w^{\prime} \theta^{\prime}}$ (Fig. 4b) gain a factor $e^{z / H}$. In the presence of a background density $\rho$, eddy transfer of momentum and temperature in the general form $\left.\left[-(1 / \rho)\left(\rho \overline{\left\langle w^{\prime} u^{\prime}\right.}\right\rangle\right)_{z}\right]$ and $\left[-(1 / \rho)\left(\rho\left\langle\overline{w^{\prime} \theta^{\prime}}\right\rangle\right)_{z}\right]$ also gain a factor $e^{z / H}$; that is, in the quasi-Boussinesq approximation, vertical profiles of eddy transfer of momentum and temperature should resemble those shown (Fig. 4), while their magnitudes are modulated by an amplifying factor. The Boussinesq approximation used here would quantitatively alter the relative strength of flow fields between different levels, but it does not qualitatively change the main results regarding azimuthal orientation. In fact, Moncrieff (1985) showed that the effects of vertical variation of density with height can be included implicitly by transforming the quasi-Boussinesq equations from scaled height coordinates to scaled pressure 
TABLE 1. Constant and physical scaling of synoptic- and mesoscale variables in the MESD model.

\begin{tabular}{|c|c|c|c|}
\hline & Physical variables & Symbolic notation & Value \\
\hline \multirow[t]{4}{*}{ Constant } & Buoyancy frequency & $N$ & $10^{-2} \mathrm{~s}^{-1}$ \\
\hline & Height & $H$ & $\frac{16}{\pi} \approx 5 \mathrm{~km}$ \\
\hline & Dry Kelvin wave speed & $c$ & $50 \mathrm{~m} \mathrm{~s}^{-1}$ \\
\hline & Rossby parameter & $\beta$ & $2.23 \times 10^{-11} \mathrm{~s}^{-1} \mathrm{~m}^{-1}$ \\
\hline \multirow[t]{7}{*}{ Synoptic scale } & Horizontal spatial scale & $X, Y$ & $1500 \mathrm{~km}$ \\
\hline & Temporal scale & $t$ & $8.3 \mathrm{~h}$ \\
\hline & Horizontal velocity & $U, V$ & $5 \mathrm{~m} \mathrm{~s}^{-1}$ \\
\hline & Vertical velocity & $W$ & $1.6 \times 10^{-2} \mathrm{~m} \mathrm{~s}^{-1}$ \\
\hline & Pressure perturbation & $P$ & $250 \mathrm{~m}^{2} \mathrm{~s}^{-2}$ \\
\hline & Potential temperature anomalies & $\Theta$ & $3.3 \mathrm{~K}$ \\
\hline & Thermal forcing & $S^{\theta}$ & $10 \mathrm{~K}_{\text {day }}{ }^{-1}$ \\
\hline \multirow[t]{7}{*}{ Mesoscale } & Horizontal spatial scale & $x, y$ & $150 \mathrm{~km}$ \\
\hline & Temporal scale & $\tau$ & $50 \mathrm{~min}$ \\
\hline & Horizontal velocity & $u, v$ & $5 \mathrm{~m} \mathrm{~s}^{-1}$ \\
\hline & Vertical velocity & $w$ & $1.6 \times 10^{-1} \mathrm{~m} \mathrm{~s}^{-1}$ \\
\hline & Pressure perturbation & $p$ & $250 \mathrm{~m}^{2} \mathrm{~s}^{-2}$ \\
\hline & Potential temperature anomalies & $\theta$ & $3.3 \mathrm{~K}$ \\
\hline & Thermal forcing & $s^{\theta}$ & $100 \mathrm{~K} \mathrm{day}^{-1}$ \\
\hline
\end{tabular}

coordinates. Table 1 summarizes all constant and physical scaling of synoptic- and mesoscale variables in the MESD model.

\section{a. Mesoscale disturbances propagating at a tilt angle}

In the tropics, MCSs are observed to propagate at various tilt angles to the zonal direction (Houze 1975, $1977,2004)$, so it is necessary to investigate the upscale impact on the synoptic-scale circulation of mesoscale disturbances that propagate at various tilt angles. The model setup for mesoscale dynamics follows Yang and
Majda (2018), and Figs. 2-4 are just altered from Figs. 2-4 of Yang and Majda (2018).

In Fig. 2a, the red arrow indicates the direction of horizontal propagation of the mesoscale disturbances as they propagate horizontally. A reference frame with $x^{\prime}$ and $y^{\prime}$ axes is introduced so that mesoscale disturbances propagate along the positive direction of the $x^{\prime}$ axis. The mesoscale heating is prescribed by the first and second baroclinic modes in Fig. 2b, whose explicit expressions are included in Table 2. The front-to-rear-tilted mesoscale heating mimics the life cycle that ranges from (a)

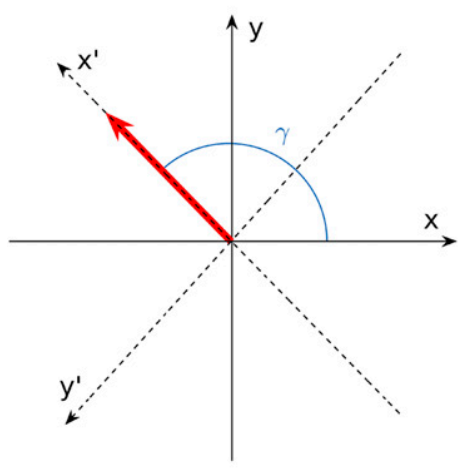

(b)

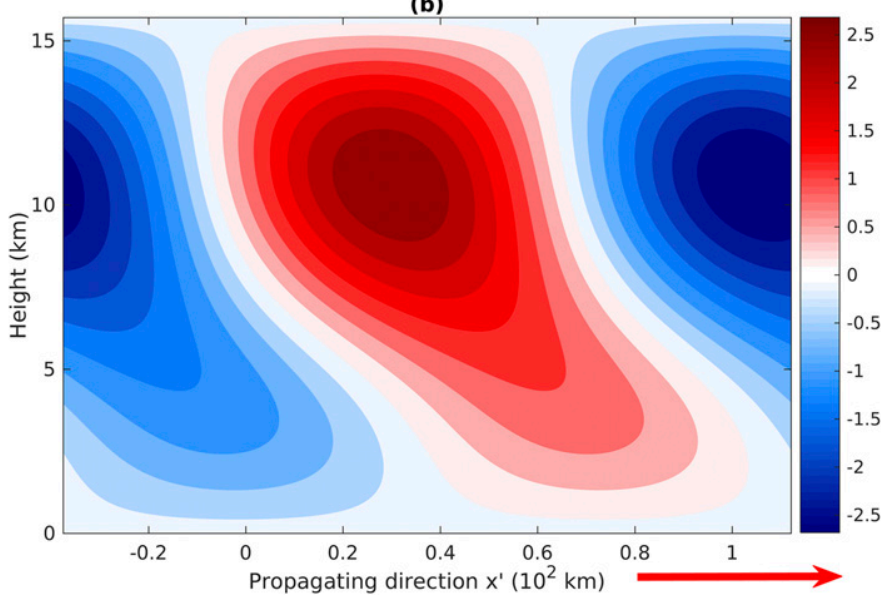

FIG. 2. Vertical profile of mesoscale heating in the new reference frame. (a) The normal reference frame is denoted by $x$ axis (east) and $y$ axis (north) (solid lines). The new reference frame with $x^{\prime}$ axis and $y^{\prime}$ axis (dashed lines) is derived by rotating the normal reference frame counterclockwise by an angle $\gamma$. The red bold arrow shows the propagation direction of mesoscale heating. (b) The vertical profile of mesoscale heating in the new reference frame. The dimensional unit is $100 \mathrm{~K}_{\text {day }}{ }^{-1}$. (From Yang and Majda 2018). 
(a)

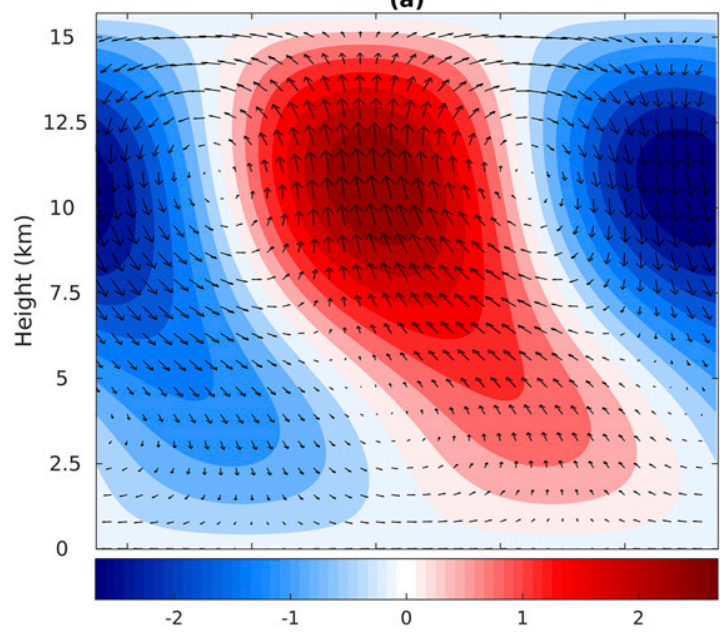

(b)



FIG. 3. Vertical profiles of (a) zonal and vertical velocity (arrows) and (b) potential temperature anomalies (contours) along the propagation direction of mesoscale heating. The color in both panels shows mesoscale heating. The maximum magnitudes of zonal and vertical velocity are 3.72 and $0.47 \mathrm{~m} \mathrm{~s}^{-1}$, respectively. The contour interval of potential temperature anomalies is $0.1 \mathrm{~K}$. The dimensional unit of mesoscale heating is $100 \mathrm{~K} \mathrm{day}^{-1}$. (From Yang and Majda 2018).

congestus to deep to stratiform clouds, and its topheavy vertical structure is consistent with the observed fact that stratiform precipitation contributes up to $40 \%$ of the total precipitation in MCSs (Houze 1977). The mesoscale heating is uniform along the direction perpendicular to its propagation direction for simplification purposes.

Figure 3 shows vertical profiles of the mesoscale circulation response including zonal and vertical velocity and potential temperature anomalies driven by the
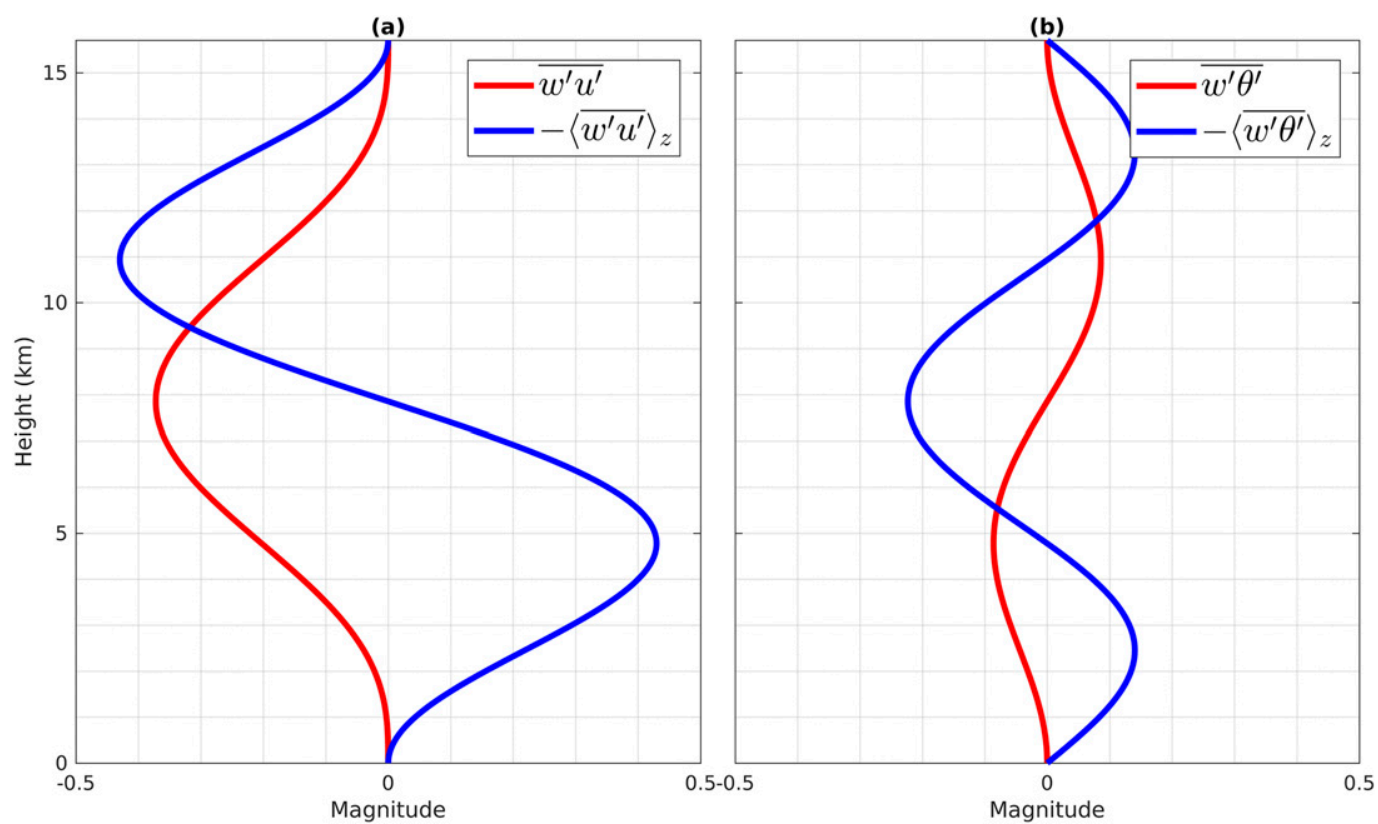

FIG. 4. Vertical profiles of eddy transfer of momentum and temperature in the case with eastward-propagating mesoscale disturbances. (a) Eddy transfer of zonal momentum (blue) and the associated eddy momentum flux (red), and (b) eddy transfer of temperature (blue) and the associated eddy heat flux (red). One dimensionless unit of eddy transfer of momentum and temperature is $15 \mathrm{~m} \mathrm{~s}^{-1}$ day ${ }^{-1}$ and $10 \mathrm{~K} \mathrm{day}^{-1}$, respectively. (From Yang and Majda 2018). 
TABLE 2. Explicit expressions of mesoscale heating and eddy transfer of horizontal momentum and temperature from Yang and Majda (2018).

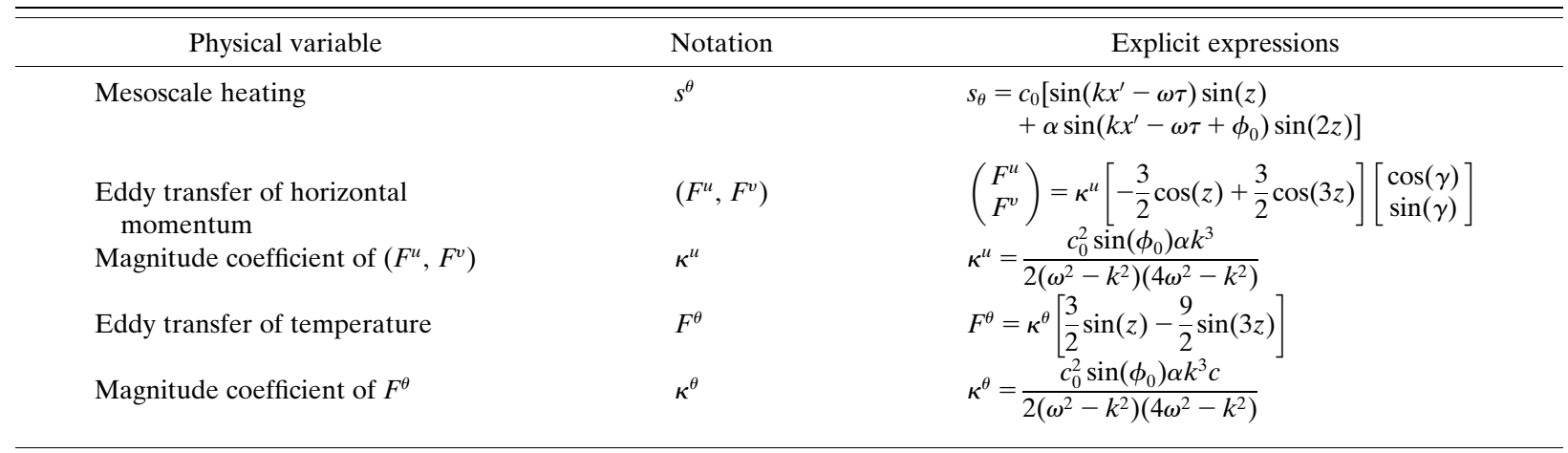

mesoscale heating in the $x^{\prime}$ and $y^{\prime}$ reference frames. As shown by Fig. 3a, heating (cooling) regions are dominated by upward and backward (downward and forward) flows throughout the whole troposphere. Lowlevel inflow is toward heating regions, gradually ascends, and eventually diverges in the upper troposphere. This deep slantwise ascending inflow layer has been shown to be important for maintaining a mature MCS (Moncrieff 1978, 1981; Crook and Moncrieff 1988; Moncrieff 1992). Both zonal and vertical velocities attain maximum strength in the upper troposphere, consistent with the top-heavy vertical profile of mesoscale heating as shown in Fig. 2b. Figure 3b shows potential temperature anomalies reach their maximum magnitude in both the upper and lower troposphere, significantly dominated by the second baroclinic mode. The vertical profile with warm anomalies on top of cold anomalies resembles realistic features of potential temperature anomalies driven by stratiform precipitation on top of rain evaporation below. Moreover, these anomalies are out of phase with heating/ cooling regions with positive anomalies preceding heating regions and trailing cold anomalies (Houze 2004).

\section{b. Upscale impact of mesoscale fluctuations of momentum and temperature}

Three eddy terms in the synoptic-scale momentum and thermal equations in Eqs. (1a)-(1c) represent the upscale impact of mesoscale fluctuations of momentum and temperature that accumulate in time. Yang and Majda (2018) showed that, in general, eddy transfer of horizontal momentum $\left(F^{u}, F^{v}\right)$ is along the same direction as the tilt angle $\gamma$,

$$
\left(\begin{array}{l}
F^{u} \\
F^{v}
\end{array}\right)=\kappa^{u}\left[-\frac{3}{2} \cos (z)+\frac{3}{2} \cos (3 z)\right]\left[\begin{array}{c}
\cos (\gamma) \\
\sin (\gamma)
\end{array}\right]
$$

while eddy transfer of temperature is independent of the tilt angle. Here we focus on $\gamma=0$ (eastward) simply because the remaining tilt angles have the same vertical profiles of eddy transfer of horizontal momentum and just shift their directions by $\gamma$. Explicit expressions of eddy transfer of momentum and temperature are included in Table 2.

Figure 4a shows that the vertical profile of eddy transfer of zonal momentum with $\gamma=0$ attains maximum eastward momentum forcing at a height of $5 \mathrm{~km}$, maximum westward momentum forcing at a height of $11 \mathrm{~km}$, and vanishes at the upper and lower boundaries. The associated eddy momentum fluxes $\overline{u^{\prime} w^{\prime}}$ are all negative with maximum strength in the middle troposphere, consistent with the upward (downward) motion being correlated with backward (forward) motion in the heating (cooling) regions as shown in Fig. 3. A similar vertical profile of eddy transfer of zonal momentum occurs in the idealized two-dimensional cloud-resolving simulations of Grabowski and Moncrieff (2001). Figure 4b shows the vertical profile of eddy transfer of temperature with cooling in the middle troposphere and heating in both the upper and lower troposphere. In particular, the low-level heating suppresses shallow congestus convection by reducing CAPE and increasing the saturation rate of water vapor.

\section{Symmetric 2-day waves with embedded mesoscale disturbances}

In this section, the equations for synoptic-scale dynamics in Eqs. (1a)-(1e) model the synoptic-scale circulation response to mean heating and the upscale impact of embedded mesoscale disturbances that propagate at various directions. The mean heating is prescribed to propagate only westward, mimicking large-scale diabatic heating associated with the westward-moving 2-day waves. Although mesoscale heating is allowed to propagate at a tilt angle, its magnitude is assumed to be modulated by the westward-moving synoptic-scale envelope, 

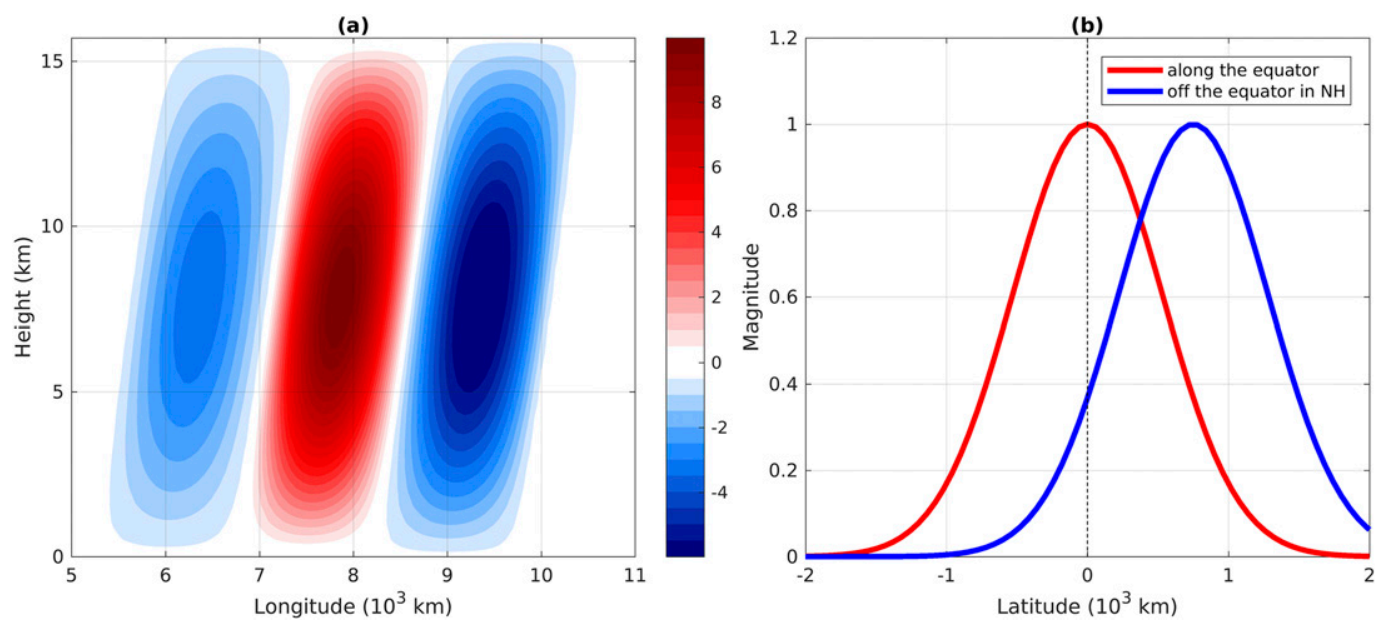

FIG. 5. Spatial structure of prescribed mean heating profile on the synoptic scale. (a) Vertical profile along the equator and (b) meridional profile in both symmetric and asymmetric cases. The mean heating in (a) has dimensional units of $\mathrm{K} \mathrm{day}^{-1}$, while that in (b) is dimensionless.

similar to Yang and Majda (2018); that is, the mesoscale heating translates westward with the same group velocity as the mean heating.

All numerical simulations are conducted in a domain with a zonal extent of $15000 \mathrm{~km}$ and a vertical extent of $15.7 \mathrm{~km}$. In the meridional direction, the solutions are assumed to decay with latitude. As for numerical resolution, there are a total of $201 x$ grids with equal $75-\mathrm{km}$ grid spacing and $31 z$ grids with equal $0.52-\mathrm{km}$ grid spacing. In the meridional direction, the solutions are projected onto the parabolic cylinder functions up to the first 30 modes. The simulations are initialized from the state of rest and ran for 13.83 days to reach an equilibrium state.

\section{a. 2-day waves driven by mean heating}

Consistent with the two-scale organization of tropical convection in 2-day waves, the MESD model provides a two-scale framework and simulates 2-day waves as the synoptic-scale circulation response to both mean heating and eddy transfer of momentum and temperature. Here a simple mean heating is prescribed to drive synoptic-scale circulation to capture the leading-order behavior of symmetric 2-day waves observed in nature, including a zonal wavelength of $2000-4000 \mathrm{~km}$, a westward propagation speed of $10-30 \mathrm{~m} \mathrm{~s}^{-1}$, a tilted middleheavy heating, and an equatorial deformation radius of $7^{\circ}$ (Takayabu 1994b; Takayabu et al. 1996; Haertel and Kiladis 2004; Kiladis et al. 2009).

Figure 5a shows the vertical profile of prescribed mean heating (measured in time tendency of potential temperature) in the longitude-height diagram, which has a zonal wavelength of $3000 \mathrm{~km}$, front-to-rear tilts, and an $18 \mathrm{~m} \mathrm{~s}^{-1}$ westward propagation speed. The middle-heavy heating dominates, accompanied by cooling to the east and west. The meridional profile of mean heating in Fig. 5b is assumed to be a Gaussian function $e^{-4 y^{2}}$, reaching its maximum value at the equator and decaying as the latitude goes poleward.

Figure 6 shows vertical profiles of all flow fields driven by the prescribed mean heating in the longitude-height diagram. As shown in Fig. 6a, zonal velocity tilts to the east with height, resembling that observed in nature (Haertel and Kiladis 2004). To the west, surface-level zonal wind convergence occurs near longitude $X=7 \times$ $10^{3} \mathrm{~km}$, with weak zonal wind divergence at its eastern and western sides. As a counterpart, the top-level zonal wind divergence occurs near longitude $X=8 \times 10^{3} \mathrm{~km}$. Vertical velocity in Fig. 6b has a similar spatial pattern as the mean heating in Fig. 5. Dominant upward motion occurs in the middle of the domain with weak downward motion to the east and west. Distinct from the in-phase relation between vertical velocity and mean heating, positive potential temperature anomalies in Fig. $6 \mathrm{c}$ lead the mean heating to the west, consistent with observations (Haertel and Kiladis 2004). The pressure perturbation in Fig. $6 \mathrm{~d}$ is characterized by negative anomalies at the lower troposphere and positive anomalies in the upper troposphere, both of which have upward and eastward tilts with height. Strong pressure perturbation occurs west of the leading edge of this system.

Figure 7 shows horizontal profiles of horizontal velocity and pressure perturbation at the surface and top of the troposphere. As shown in Fig. 7a, convergent winds dominate at the surface with its maximum magnitude at the equator, accompanied by negative pressure perturbation tilting eastward as the latitude goes poleward. The westerly winds at the leading edge to the west is 

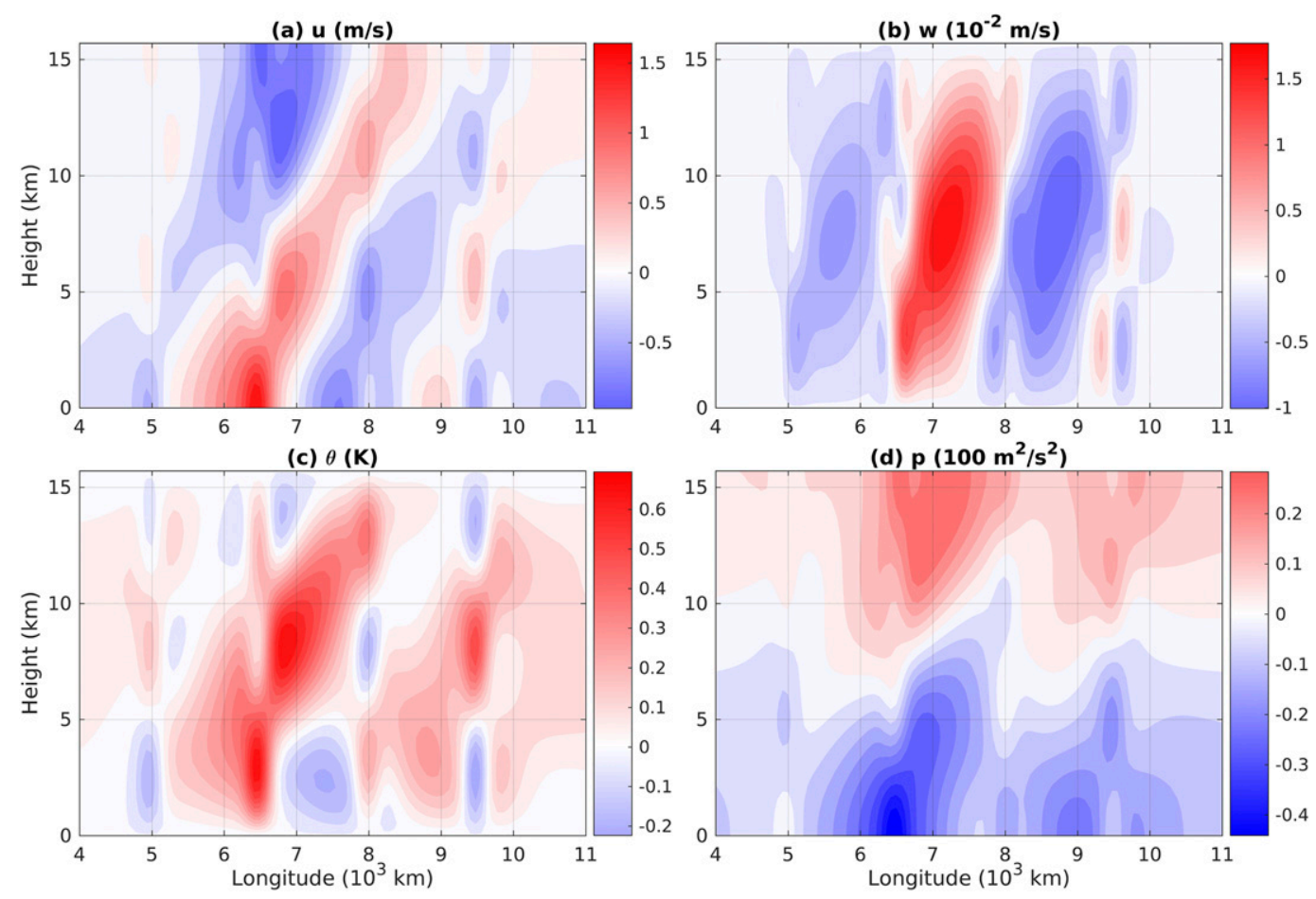

FIG. 6. Vertical cross sections of mean heating-driven flow fields at the equator in the longitude-height diagram: (a) zonal velocity, (b) vertical velocity, (c) potential temperature anomalies, and (d) pressure perturbation. The corresponding dimensional units of these flow fields are indicated in the title of each panel.

stronger than to the east. Both horizontal winds and pressure perturbation decay poleward. As its counterpart, divergent winds at the top are located to the east of the surface-level wind convergence at longitude $X=$ $7.7 \times 10^{3} \mathrm{~km}$. This mean heating-driven synoptic-scale circulation response with surface-level (top level) wind convergence (divergence) resembles the wave train pattern of the 2-day waves observed within a convective envelope (Haertel and Kiladis 2004; Kiladis et al. 2009).

\section{b. Upscale impact of mesoscale disturbances propagating at various tilt angles}

It is critical to understand the upscale impact of mesoscale disturbances that propagate at various tilt angles on symmetric 2-day waves in terms of favorability conditions for convection. Stechmann and Majda (2009) emphasized two factors that could provide favorable conditions for convection, including low-level negative potential temperature anomalies and upward motion. Particularly, three favorable conditions at various levels help interpret the results herein. First, a lowertropospheric $(2.62 \mathrm{~km})$ negative potential temperature anomaly is favorable for congestus convection through CAPE generation. Second, midtropospheric inflow $(5.24 \mathrm{~km})$ increases the entrainment of environmental air and maintains the large CAPE when the environment is moist. Third, an upper-tropospheric $(7.85 \mathrm{~km})$ negative potential temperature anomaly is favorable for deep convection.

Figure 8 shows potential temperature anomalies induced by mean heating and eddy terms at a height of $2.62 \mathrm{~km}$ in the longitude-latitude diagram. The potential temperature anomalies in Fig. $8 \mathrm{a}$ are characterized by alternate anomalies in the zonal direction, particularly with positive (negative) anomalies to the west (east) of wind convergence at $X=7 \times 10^{3} \mathrm{~km}$, while those induced by eddy terms vary with tilt angle. In the cases where mesoscale disturbances propagate at a tilt angle close to the eastward direction (e.g., $0^{\circ}$ and $30^{\circ}$ ), negative anomalies are induced west of the convective envelope. This provides a favorable condition for congestus convection in a moist environment and promotes the westward propagation of the convective envelope. In contrast, a tilt angle close to the westward direction (e.g., $180^{\circ}, 150^{\circ}$ ) induces positive anomalies at the leading edge, suppressing convection by decreasing CAPE and increasing the saturation rate of water vapor. In the intermediate cases (e.g., $60^{\circ}, 90^{\circ}, 120^{\circ}$ ), positive (negative) anomalies in strong (weak) magnitude that are induced in the $\mathrm{NH}(\mathrm{SH})$ introduce meridional asymmetry of favorable conditions for convection and explain the southward displacement of observed 2-day 

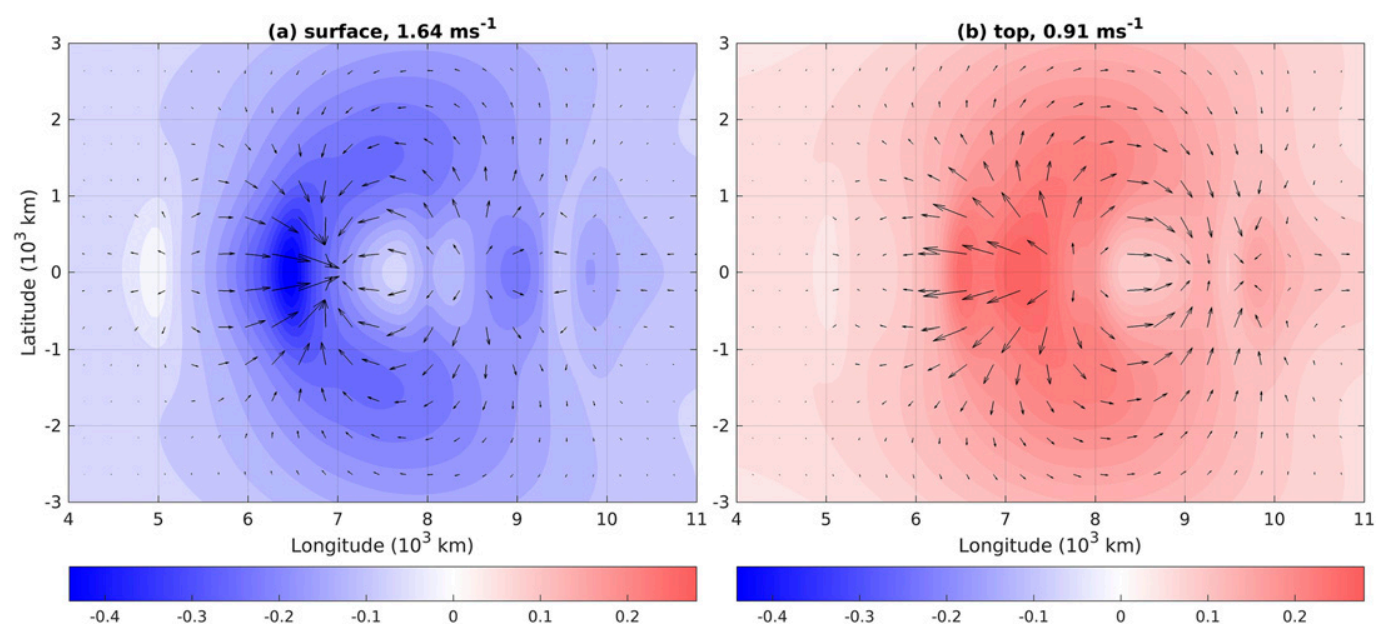

FIG. 7. Horizontal sections of mean heating-driven horizontal velocity and pressure perturbation: (a) the surface and (b) the top of the domain. Horizontal velocity is indicated by arrows, while pressure perturbation is indicated by color. The dimensional units of horizontal velocity and pressure perturbation are $\mathrm{m} \mathrm{s}^{-1} \mathrm{and} \mathrm{m}^{2} \mathrm{~s}^{-2}$, respectively.

waves (Takayabu 1994b; Takayabu et al. 1996; Haertel and Kiladis 2004). Results with the remaining tilt angles (larger than $180^{\circ}$ ) can be inferred directly from the argument of symmetry.

Cold potential temperature anomalies in the upper troposphere favor deep convection by CAPE buildup. Figure 9 shows horizontal profiles of upper-tropospheric $(7.85 \mathrm{~km})$ potential temperature anomalies induced by mean heating and eddy terms in the longitude-latitude diagrams. The spatial patterns of potential temperature anomalies induced by eddy terms in Figs. $9 \mathrm{~b}-\mathrm{f}$ are similar to those in Figs. 8b-f but are of opposite sign, meaning that the associated favorability conditions for convection are simply opposite. In particular, eastwardpropagating mesoscale disturbances tend to induce upper-level warm anomalies to the west, suppressing deep convection at the leading edge of the convection envelope.

Figure 10 shows low-level vertical velocity induced by mean heating and eddy terms at a height of $2.62 \mathrm{~km}$ at various tilt angles. As shown by Fig. 10a, the horizontal profile of vertical velocity resembles that of mean heating with positive anomalies in the middle and negative anomalies on both the eastern and western sides. At tilt angles of $0^{\circ}-30^{\circ}$ in Figs. $10 \mathrm{~b}$ and $10 \mathrm{c}$, the vertical motion induced by eddy terms is in phase with that induced by mean heating but of opposite sign, weakening vertical motion induced by mean heating. In particular, this extra upward motion at the leading edge mechanically lifts moist air parcels in a moist environment and favors tropical convection as the whole system propagates westward. The effects at tilt angles of $120^{\circ}-180^{\circ}$ in Figs. 10f-h are simply opposite. In the intermediate cases with tilt angles of $60^{\circ}-90^{\circ}$ in Figs. $10 \mathrm{~d}$ and $10 \mathrm{e}$, the vertical velocity is significantly reduced by the competing effects between eddy transfer of momentum and temperature.

Figure 11 shows horizontal profiles of surface-level horizontal velocity and pressure perturbation induced by mean heating and eddy terms in the longitudelatitude plane. First, the horizontal velocity induced by eddy terms in Figs. 11b-h is much weaker than that induced by mean heating in Fig. 11a. Particularly, in the cases with eastward-propagating mesoscale disturbances in Fig. 11b, there exists wind convergence to the west and wind divergence to the east, resulting in the westward displacement of total wind convergence relative to the heating center, resembling observations (Haertel and Kiladis 2004). Meanwhile, negative pressure perturbation induced inside the synoptic-scale envelope has a ring shape.

Figure 12 shows horizontal profiles of midtropospheric $(5.24 \mathrm{~km})$ horizontal velocity and pressure perturbation induced by mean heating and eddy terms. Similar to Fig. 11a, the horizontal winds induced by mean heating in the middle troposphere in Fig. 12a are also characterized by wind convergence in the heating region in weaker magnitude. As for the eddy terms, persistent westerly winds are induced with eastward propagation in Fig. 12b. In reality, such extra westerly winds tend to increase the entrainment of environmental air and maintain the large CAPE when the environment is moist. Also, westerly winds in an upward/ eastward tilt form between the surface and the middle troposphere. As for the remaining cases in Figs. 12c-h, the resulting wind jets are all along the propagation direction of mesoscale disturbances. Furthermore, a clockwise circulation cell is found at the right side of 

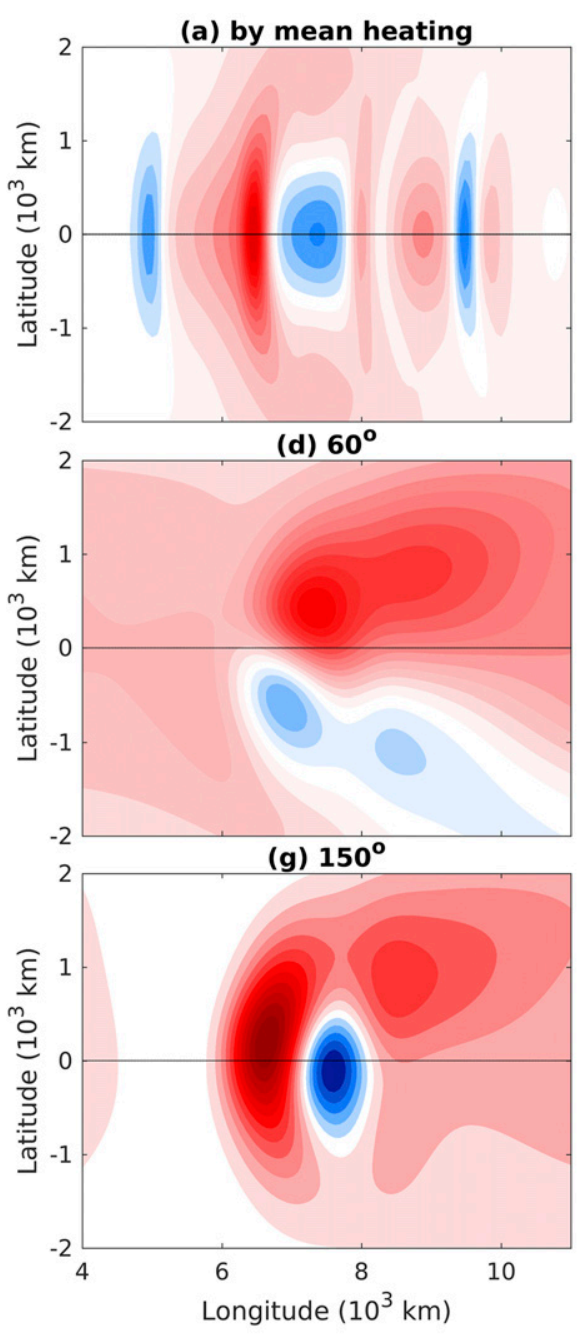

(b) $0^{\circ}$

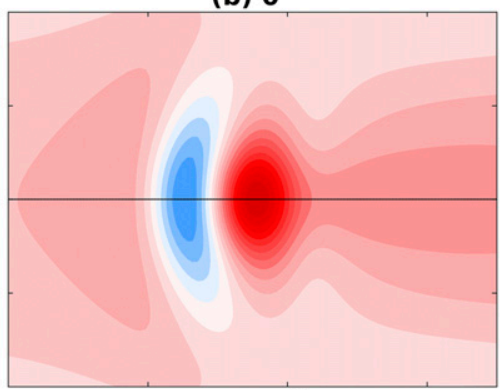

(e) $90^{\circ}$

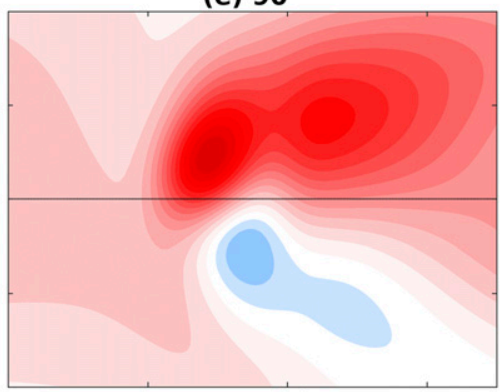

(h) $180^{\circ}$

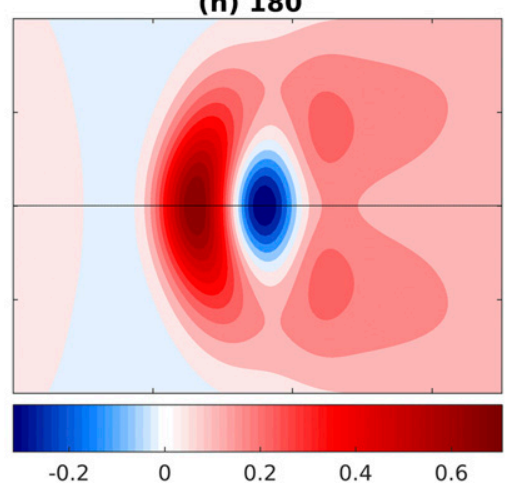

(c) $30^{\circ}$

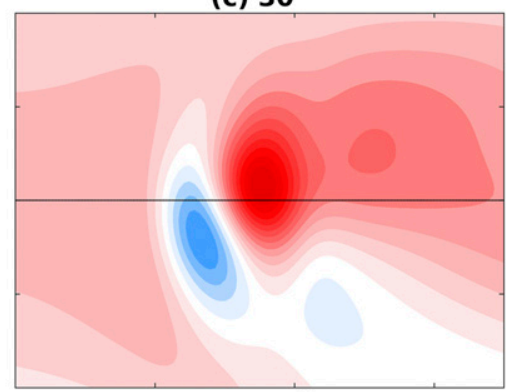

(f) $120^{\circ}$

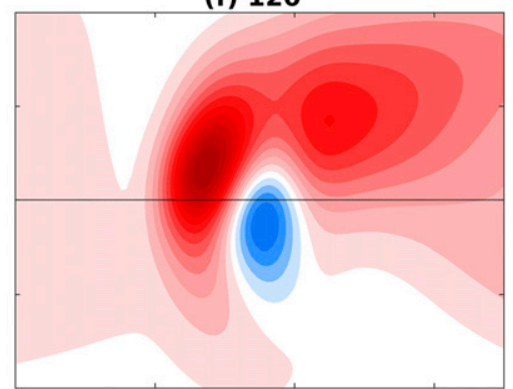

(i)

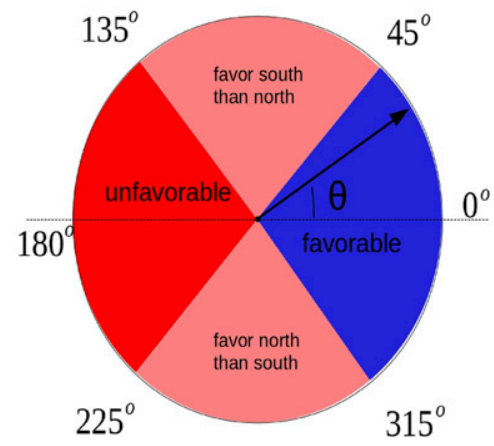

FIG. 8. Horizontal sections of potential temperature anomalies in the lower troposphere $(2.62 \mathrm{~km})$ in the longitude-latitude diagram. (a) Anomalies induced by mean heating, (b)-(h) anomalies induced by eddy terms at tilt angles from $0^{\circ}$ to $180^{\circ}$, respectively. (i) Summary of favorability of convection in different tilt-angle cases (blue: favorable; pink: unfavorable, asymmetric; red: unfavorable). The dimensional unit of potential temperature anomalies is $\mathrm{K} ; 90^{\circ}$ refers to north.

wind jets. Particularly, in Fig. 12d, such clockwise flows provide favorable conditions for tropical cyclogenesis in the SH.

\section{c. Tilts in the presence of upright mean heating}

A key feature of 2-day waves is the front-to-rear tilt throughout the troposphere (Haertel and Kiladis 2004). It is intriguing to investigate whether the tilted vertical structure of the synoptic-scale circulation response is induced by mean heating or the upscale impact of mesoscale disturbances. Herein, only cases with upright top-heavy mean heating are considered. This upright mean heating consists of the first and second baroclinic modes, $\sin (z)+\alpha \sin (2 z)$, where $\alpha=-0.5$, representing the significant contribution from deep and stratiform convection in precipitation (Tokay and Short 1996).
The results show that even with an upright mean heating, a tilted synoptic-scale circulation structure can be realized when the mesoscale disturbances travel in certain directions.

Figure 13 shows vertical profiles of potential temperature anomalies induced by the upright mean heating and eddy terms in the longitude-height diagram. As shown by Fig. 13a, the mean heating potential temperature anomalies are characterized by warm (cold) anomalies in the upper (lower) troposphere, resembling upper-tropospheric stratiform heating and lowertropospheric cooling as a result of rain evaporation. For the $90^{\circ}-180^{\circ}$ tilt-angle range in Figs. $13 \mathrm{c}$ and $13 \mathrm{~d}$, potential temperature anomalies to the west are dominated by the third baroclinic mode, while those to the east are weak. In the case with a tilt angle of $60^{\circ}$ in 

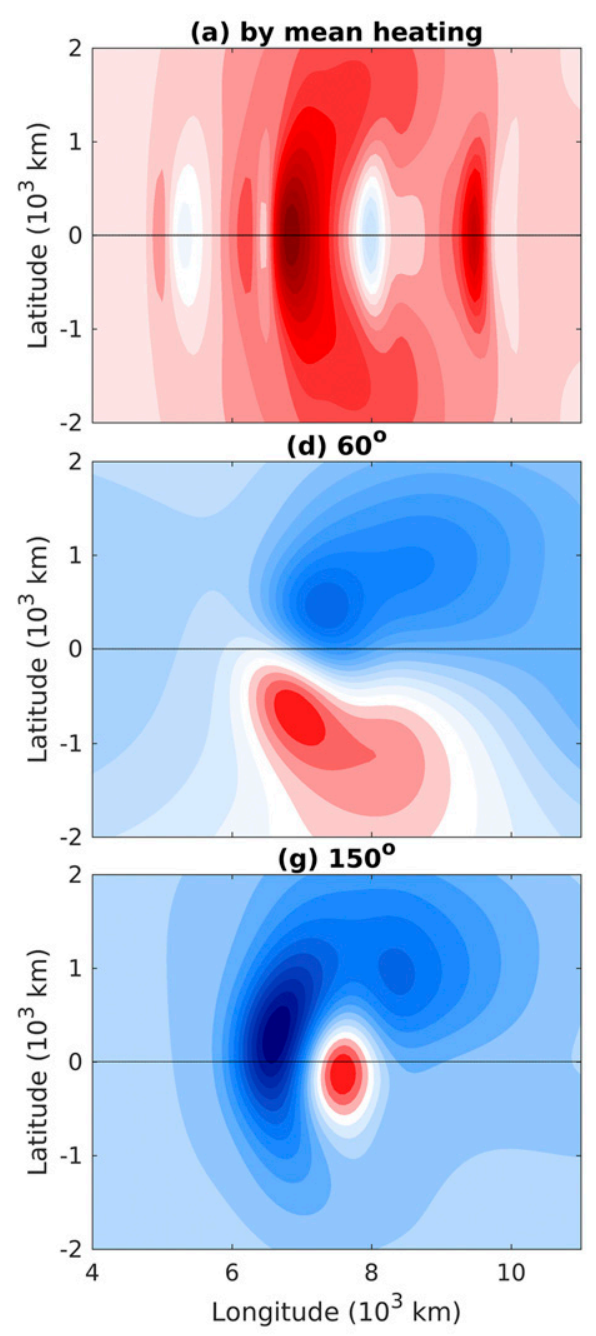

(b) $0^{\circ}$

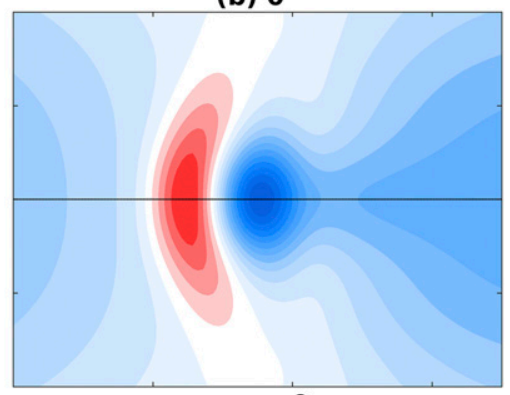

(e) $90^{\circ}$

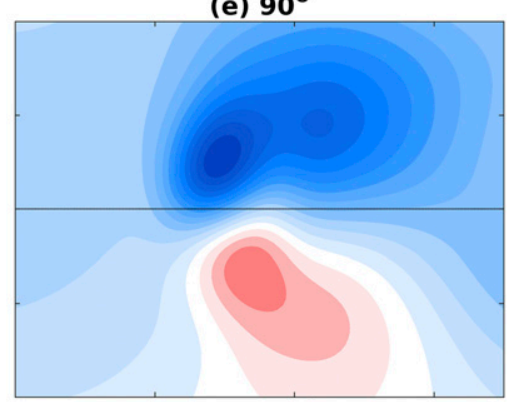

(h) $180^{\circ}$

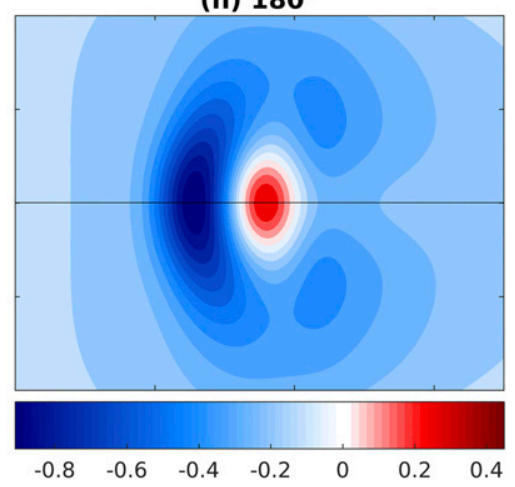

(c) $30^{\circ}$

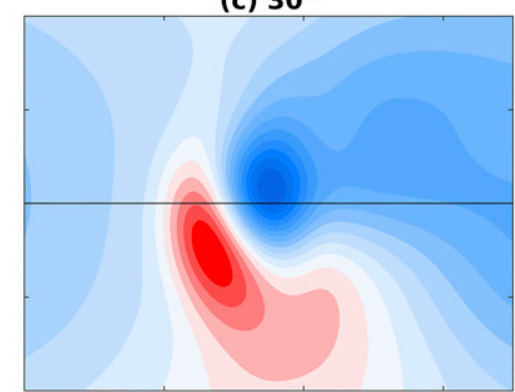

(f) $120^{\circ}$

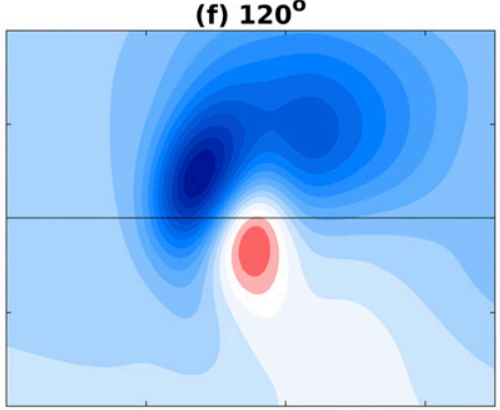

(i)

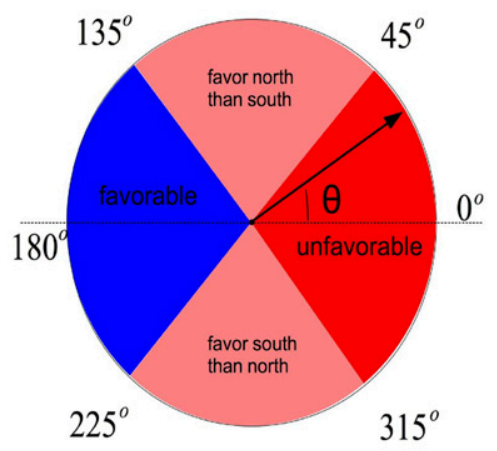

FIG. 9. As in Fig. 8, but in the upper troposphere $(7.85 \mathrm{~km})$.

Fig. 13e, these anomalies in the third baroclinic mode are located to the east. Potential temperature anomalies in the case with a tilt angle of $0^{\circ}$ in Fig. $13 \mathrm{f}$ have a similar spatial pattern further east. As for total potential temperature anomalies, the upward/eastward-tilted structure with positive anomalies on top of negative anomalies occurs only at tilt angles of $60^{\circ}$ in Fig. $13 \mathrm{i}$ and $0^{\circ}$ in Fig. 13j.

\section{Asymmetric 2-day waves with embedded mesoscale disturbances during boreal summer}

The effects of the Coriolis force on the synoptic-scale circulation increases with latitude, in regard to winds, pressure, and potential temperature. The goal of this section is to consider the scenario when both mean heating and mesoscale heating are located north of the equator, mimicking 2 -day waves that propagate in the $\mathrm{NH}$ during boreal summer. Both mean heating and the synoptic-scale envelope modulating mesoscale heating are prescribed to propagate only westward in the $\mathrm{NH}$, mimicking the westward-moving 2-day waves over the WP. It is intriguing how the upscale impact of mesoscale disturbances in asymmetric 2-day waves differs from that in the symmetric waves. Here the mean heating has the same vertical profile as in Fig. 5a and the asymmetric meridional profile prescribed by a Gaussian function $e^{-4(y-0.5)^{2}}$, shown in Fig. 5b. The 750-km $(0.5$ in dimensionless units) northward displacement of the maximum value is consistent with the variance distribution in Kiladis et al. (2009).

Figure 14 shows the horizontal profiles of horizontal winds and pressure perturbation as driven by the mean heating. Besides the convergent winds at the surface, significant cyclonic flows accompanied by negative pressure perturbation are induced at the leading edge of 

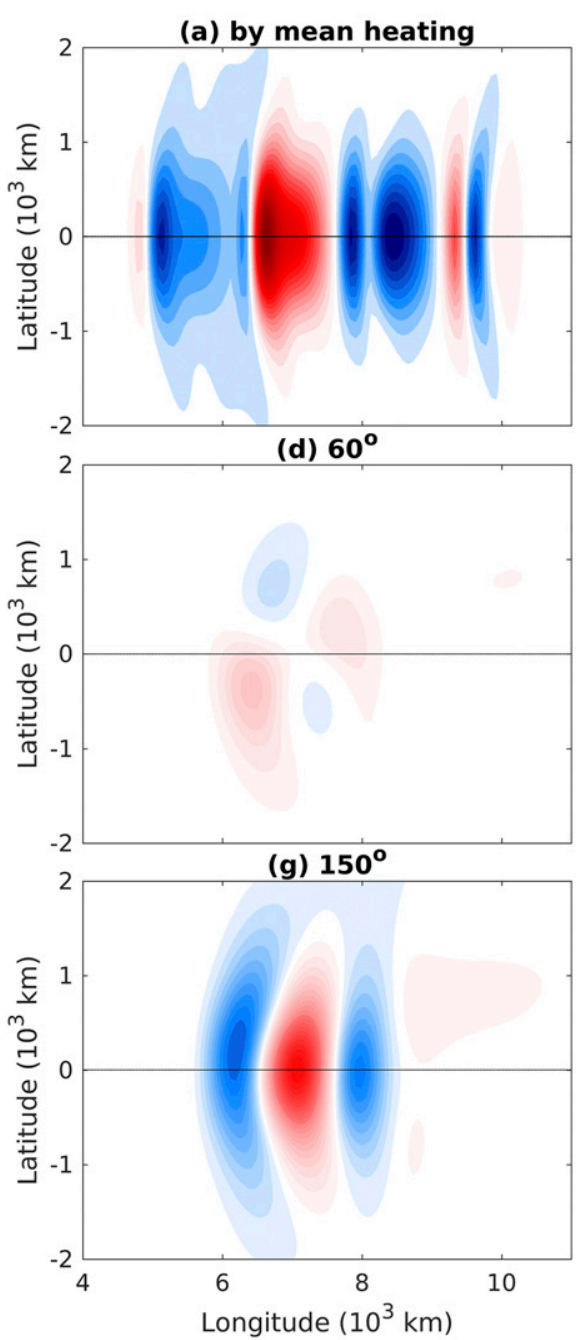

(b) $0^{\circ}$

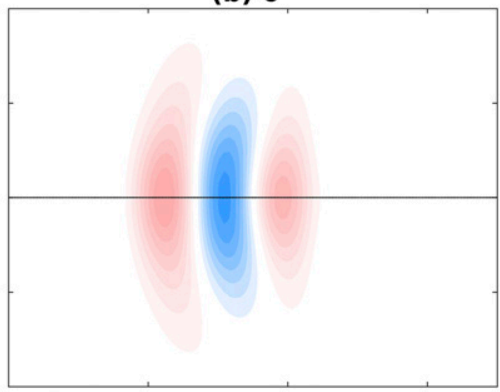

(e) $90^{\circ}$

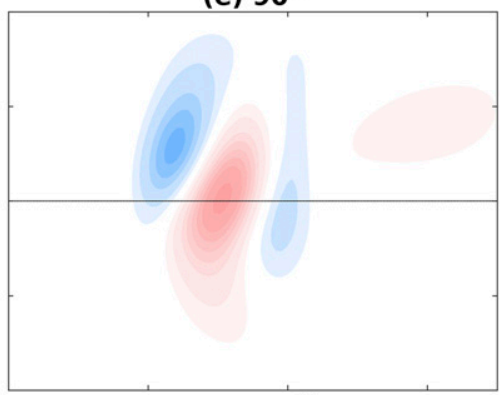

(h) $180^{\circ}$

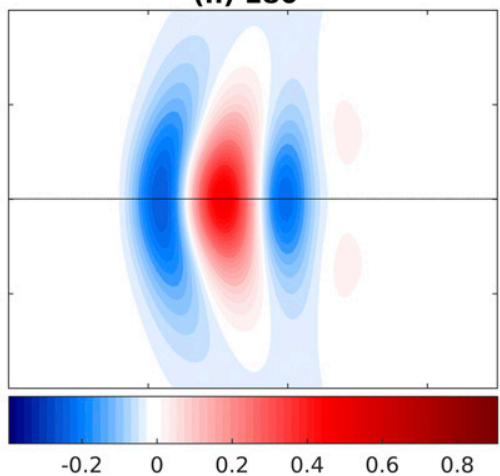

(c) $30^{\circ}$

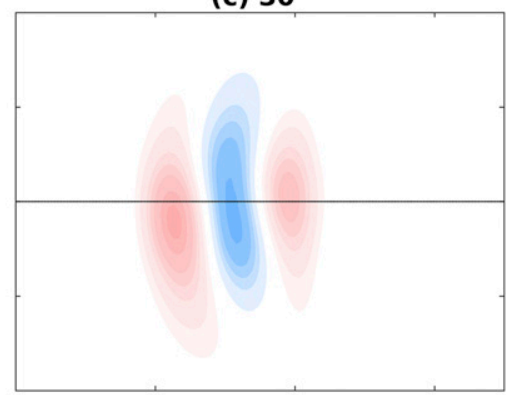

(f) $120^{\circ}$

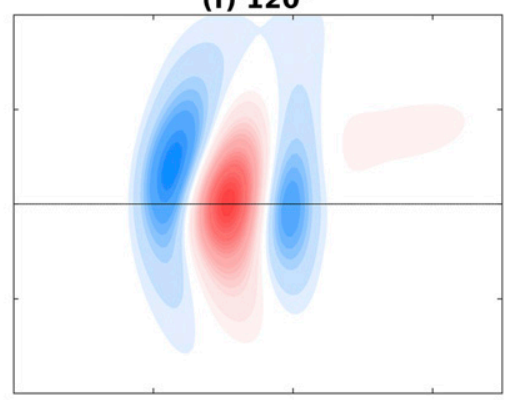

(i)

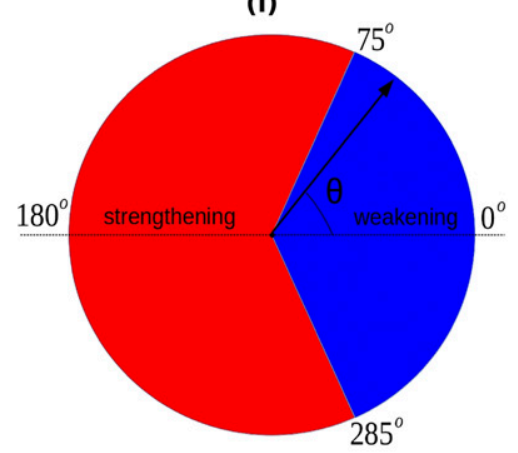

FIG. 10. As in Fig. 8, but for vertical velocity in the lower troposphere (2.62 km). (i) Summary of the impact of eddy-driven vertical velocity on mean heating-driven vertical velocity (blue: weakening; red: strengthening).

the convective envelope and its northern side under the Coriolis force. Both cyclonic flows and negative pressure perturbations induced by mean heating provide favorable conditions to precondition hurricane embryo, a similar mechanism for tropical cyclogenesis as a result of wave activity (Frank and Roundy 2006). As a counterpart, divergent winds accompanied by anticyclonic flows and positive pressure perturbation occur at the top of the domain. Besides, the winds to the north of the heating center at higher latitudes are stronger than those at lower latitudes in the $\mathrm{NH}$, indicating intensified 2-day waves off the equator.

Figure 15 shows potential temperature anomalies in the lower troposphere at a height of $2.62 \mathrm{~km}$ induced by eddy terms at various tilt angles in the longitudelatitude diagram. In the cases with tilt angles of $0^{\circ}-90^{\circ}$, the cold potential temperature anomalies induced to the west trigger shallow congestus convection at the leading edge of the convective envelope and promote its westward propagation in a moist environment. Extrawarm anomalies are induced at higher latitudes of the $\mathrm{NH}$, suppressing convection off the equator and maintaining its location close to the equator. The cases with $90^{\circ}-270^{\circ}$ tilt angles have the opposite effect on equatorial convection by suppressing convection at the leading edge of the convective envelope and triggering shallow congestus convection to the east at the trailing edge. Extrawarm anomalies occur at higher NH latitudes, while those at the $\mathrm{SH}$ are negligible. In the cases with tilt angles of $270^{\circ}-0^{\circ}$, warm anomalies are induced close to the equator, while cold anomalies in weak magnitude are induced at higher latitudes of the $\mathrm{NH}$, which provide favorable conditions for convection off the equator and 

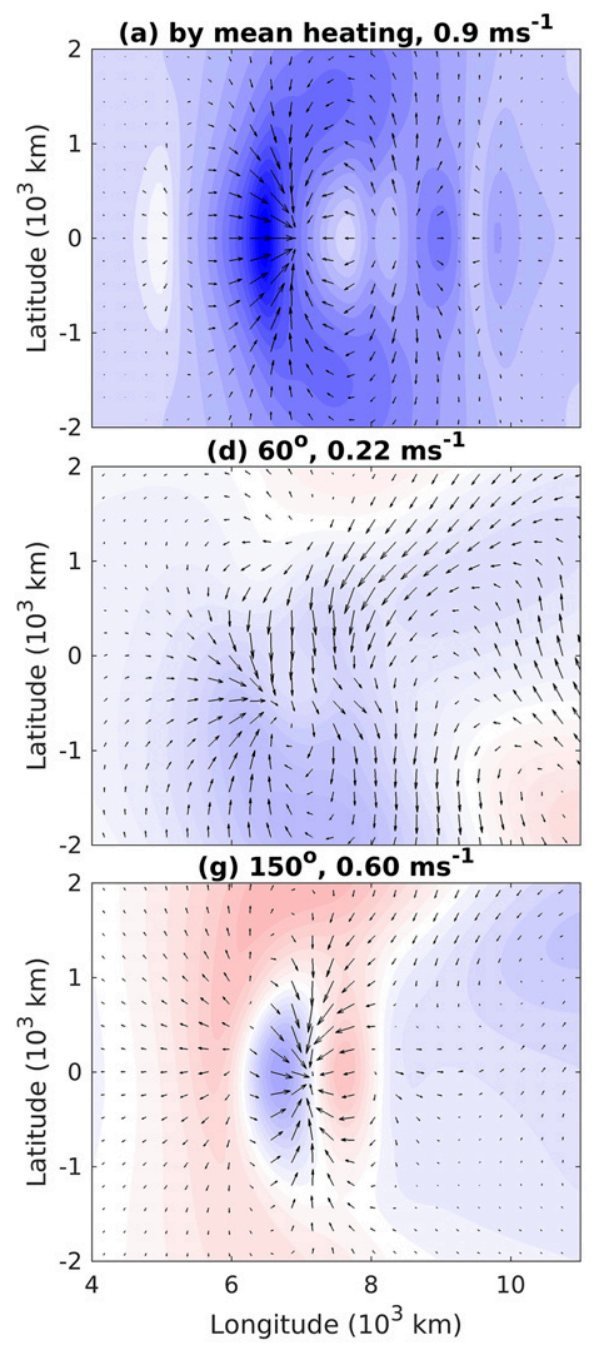

(b) $0^{\circ}, 0.26 \mathrm{~ms}^{-1}$

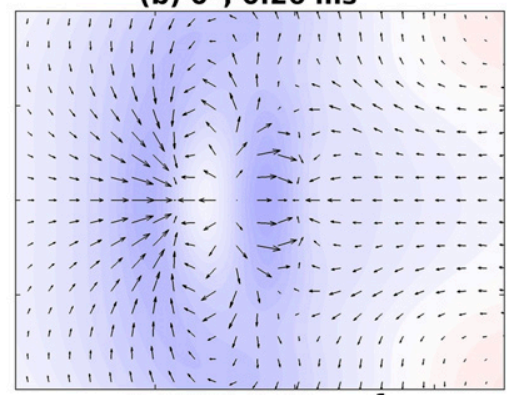

(e) $90^{\circ}, 0.36 \mathrm{~ms}^{-1}$

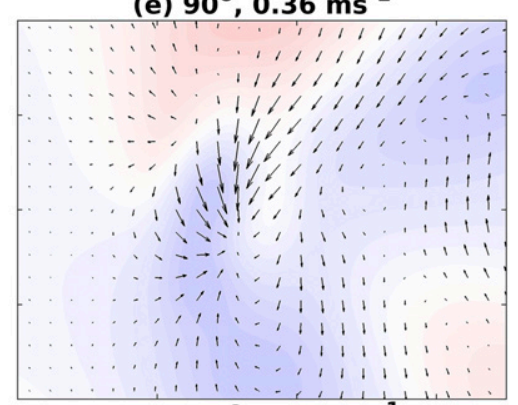

(h) $180^{\circ}, 0.60 \mathrm{~ms}^{-1}$

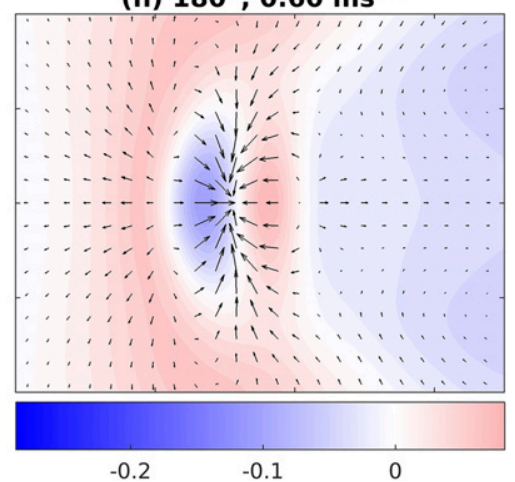

(c) $30^{\circ}, 0.25 \mathrm{~ms}^{-1}$

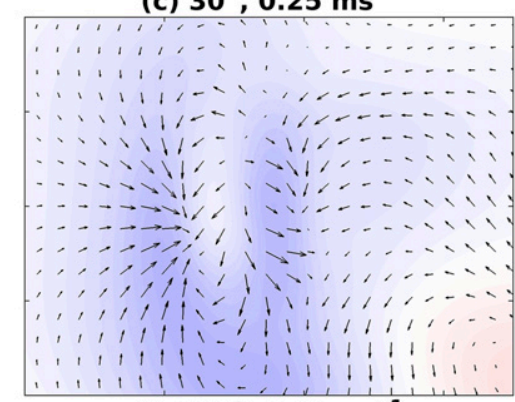

(f) $120^{\circ}, 0.50 \mathrm{~ms}^{-1}$

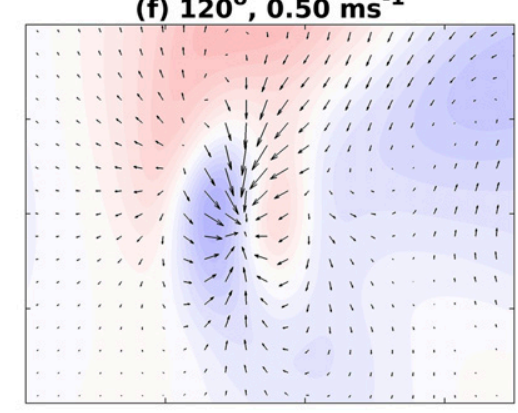

FIG. 11. Horizontal profiles of horizontal velocity and pressure perturbation at the surface $(0 \mathrm{~km})$ in the longitude-latitude diagrams. (a) Profiles induced by mean heating, and (b)-(h) profiles induced by eddy terms at tilt angles from $0^{\circ}$ to $180^{\circ}$, respectively. Horizontal velocity is shown by arrows and pressure perturbation is shown by color. The maximum magnitude of horizontal velocity is indicated in the title of each panel. The dimensional units of horizontal velocity and pressure perturbation are $\mathrm{m} \mathrm{s}^{-1}$ and $100 \mathrm{~m}^{2} \mathrm{~s}^{-2}$, respectively.

maintain its northward displacement in asymmetric 2-day waves.

\section{Tropical cyclogenesis}

The substantial meridional asymmetry resulting from the northward displacement of the heating center should occur at all levels of the synoptic-scale circulation response. As shown above, the mean heating-driven circulation provides favorable conditions for tropical cyclogenesis with cyclonic flows and negative pressure perturbation. It is important to investigate whether the upscale impact of mesoscale disturbances in the meridionally asymmetric 2-day waves can also influence tropical cyclogenesis by modifying the morphology of synoptic-scale circulation.
Figure 16 shows horizontal profiles of midtropospheric horizontal velocity and pressure perturbation induced by mean heating and eddy terms at a height of $5.24 \mathrm{~km}$. The mean heating-driven horizontal velocity in the middle troposphere in Fig. 16e is characterized by convergent winds in the heating center, accompanied by cyclonic flows and negative pressure perturbation, similar to that at the surface in Fig. 14a. As for that induced by eddy terms at various tilt angles in Figs. $16 \mathrm{a}-\mathrm{d}$ and $16 \mathrm{f}-\mathrm{h}$, the resulting horizontal velocity is generally characterized by persistent strong jets along the same propagation direction as mesoscale disturbances. Intuitively, this is consistent with the midtropospheric momentum forcing from eddy transfer of horizontal momentum in Fig. 4a. Under this extra momentum forcing, those persistent jets 

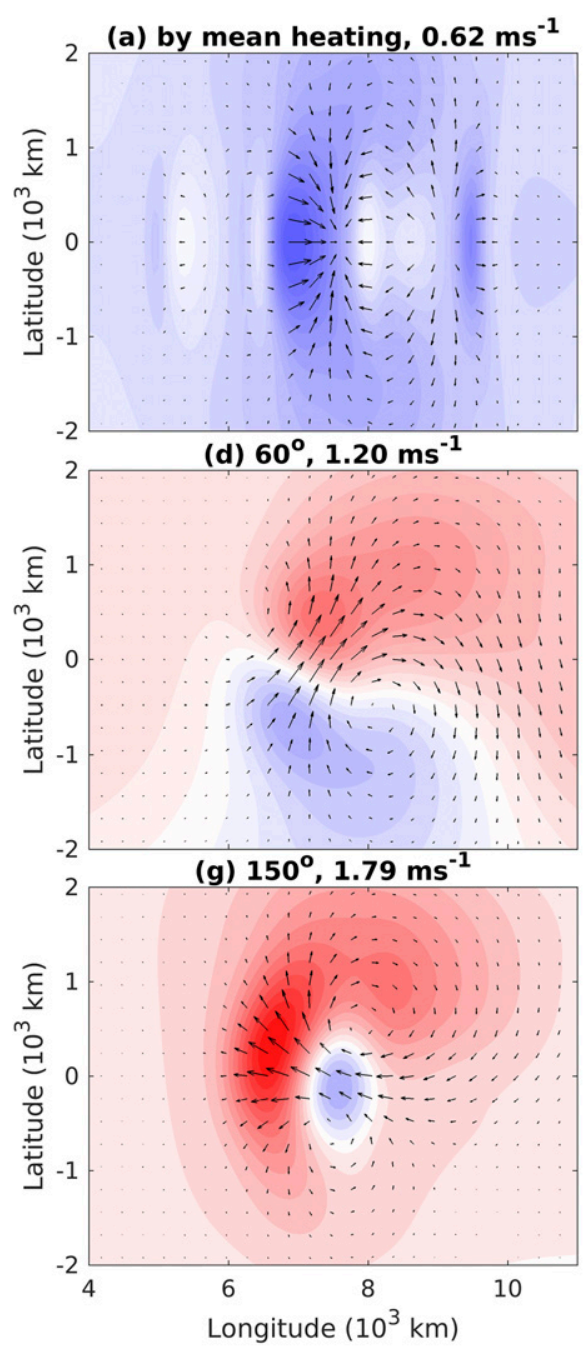

(b) $0^{\circ}, 1.64 \mathrm{~ms}^{-1}$

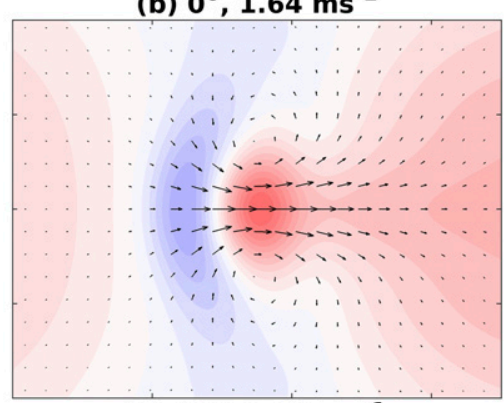

(e) $90^{\circ}, 1.11 \mathrm{~ms}^{-1}$

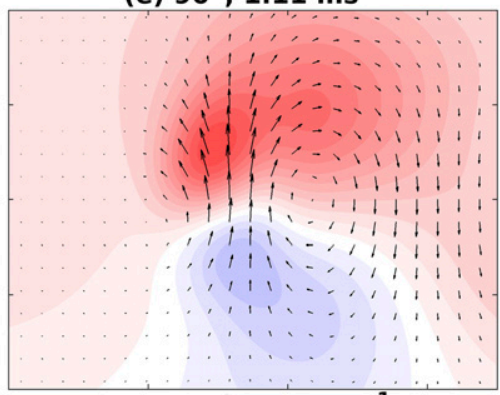

(h) $180^{\circ}, 1.97 \mathrm{~ms}^{-1}$

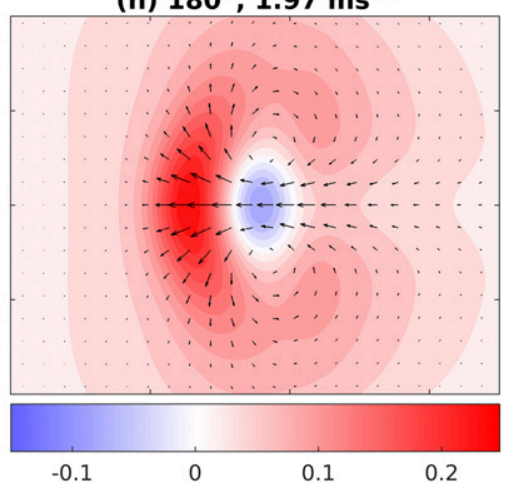

(c) $30^{\circ}, 1.51 \mathrm{~ms}^{-1}$

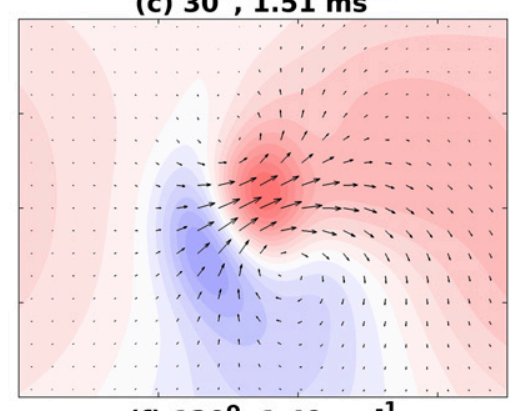

(f) $120^{\circ}, 1.49 \mathrm{~ms}^{-1}$
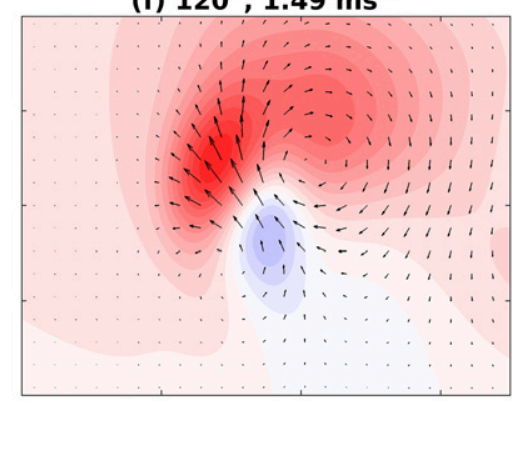

FIG. 12. As in Fig. 11, but in the middle troposphere $(5.24 \mathrm{~km})$.

actually blow from negative pressure perturbation regions to positive pressure perturbation regions.

More importantly, in the cases with tilt angles of $315^{\circ}-0^{\circ}$ in Figs. $16 \mathrm{f}$ and $16 \mathrm{~h}$, the horizontal jets are accompanied by both cyclonic flows and negative pressure perturbation at their right side in the $\mathrm{NH}$, which preconditions tropical cyclogenesis and explains the prevailing tropical cyclones in the ITCZ regions during boreal summer (Frank and Roundy 2006). These favorable preconditioning conditions for tropical cyclogenesis resulting from the upscale impact of mesoscale disturbances are distinguished from all other mechanisms, such as the vertically sheared horizontal flows (Majda et al. 2008). At the remaining tilt angles, the horizontal jets are accompanied by anticyclonic flows and positive pressure perturbation, thus suppressing tropical cyclogenesis.

\section{Upscale impact of mesoscale disturbances on 2-day waves versus CCKWs}

The MESD model is now used to simulate 2-day waves and CCKWs under a similar model setup (Yang and Majda 2018), except for their opposite propagation speeds $\left(15 \mathrm{~m} \mathrm{~s}^{-1}\right.$ for CCKWs and $-18 \mathrm{~m} \mathrm{~s}^{-1}$ for 2-day waves). An intriguing issue concerns differences in the upscale impact of mesoscale disturbances, such as convective organization and tropical cyclogenesis. The theoretical predictions about the upscale impact of mesoscale disturbances on symmetric westward-propagating 2-day waves and eastward-propagating CCKWs by the MESD model are compared, in terms of the propagation speed of mesoscale disturbances $s$ and propagation direction (tilt angle) $\gamma$. A brief summary about asymmetric 2 -day waves is also provided. 
(a) by mean heating

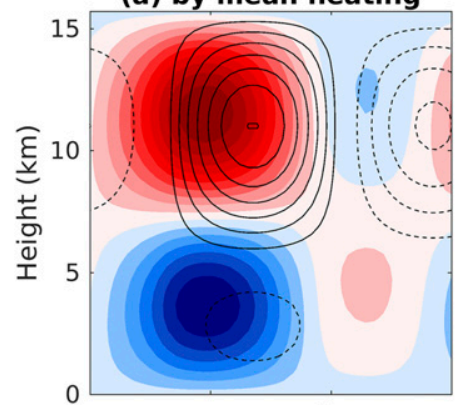

(c) $180^{\circ}$

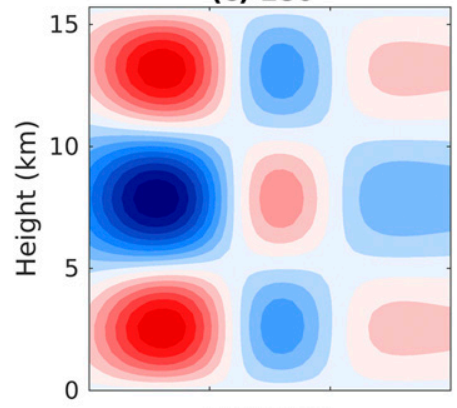

(g) total
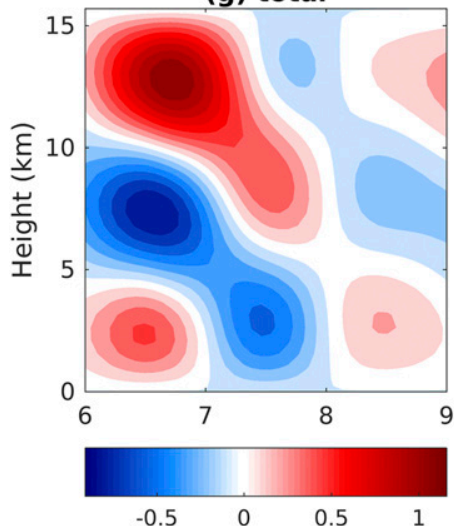

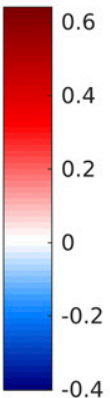

(d) $90^{\circ}$

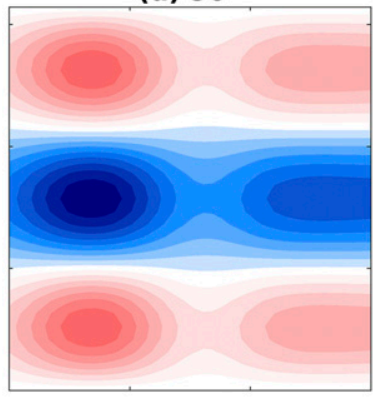

(h) total
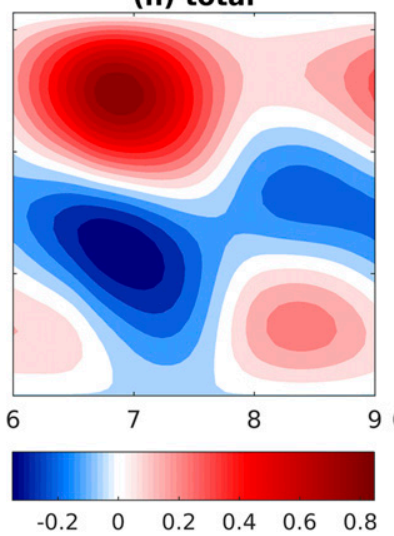

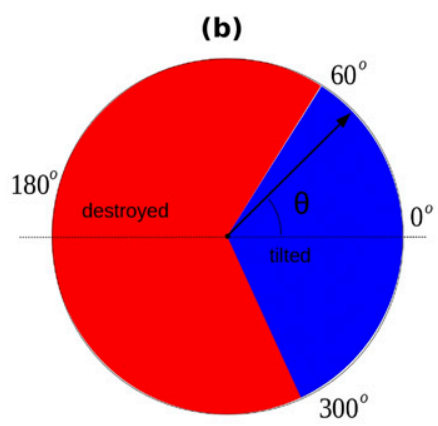

(e) $60^{\circ}$

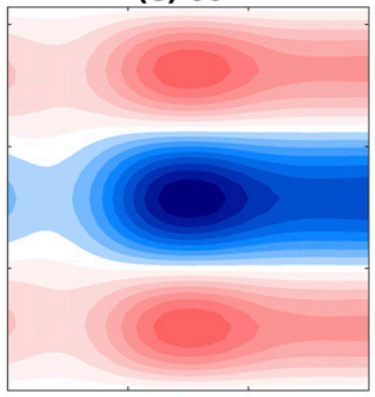

(i) total
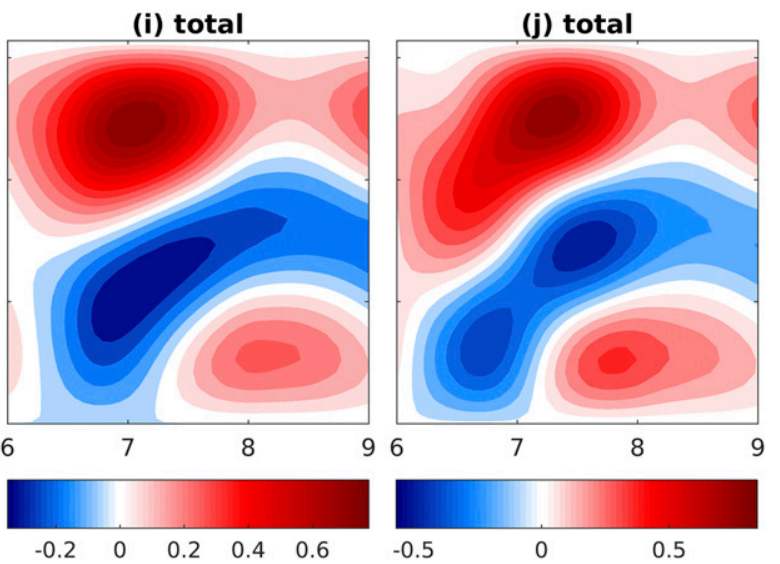

(f) $0^{\circ}$

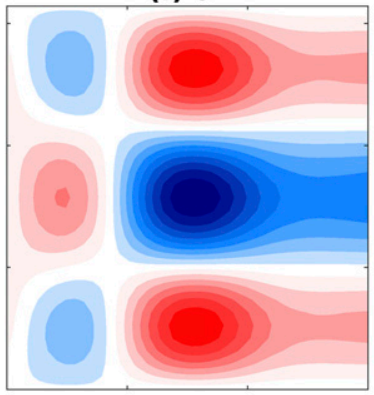

(j) total

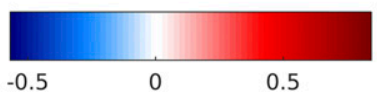

FIG. 13. Vertical profiles of potential temperature anomalies at the equator in the longitude-height diagram. (a) Top-heavy upright mean heating is indicated by contours and the resulting anomalies are shown by color. (c)-(f) Anomalies induced by eddy terms at tilt angles of $180^{\circ}, 90^{\circ}, 60^{\circ}$, and $0^{\circ}$, respectively. (g)-(j) Total anomalies induced by both top-heavy upright mean heating and eddy terms in the same column. (b) Summary of the upscale impact of mesoscale disturbances on the vertical structure of potential temperature anomalies (blue: tilted; red: destroyed). The dimensional unit is $\mathrm{K}$.

Table 3 compares the upscale impact of mesoscale disturbances that propagate at various tilt angles and speeds on symmetric 2-day waves and CCKWs in terms of favorability for convection. Both slow propagation $\left(s<12 \mathrm{~m} \mathrm{~s}^{-1}\right)$ and fast propagation $\left(s \geq 12 \mathrm{~m} \mathrm{~s}^{-1}\right)$ scenarios are considered. According to Yang and Majda (2018), the ratio of eddy transfer of temperature and momentum in dimensionless units is proportional to the propagation speed of mesoscale disturbances $s$. In the slow propagation scenario, eddy transfer of momentum dominates the upscale impact resulting from mesoscale fluctuations. By comparing Fig. 6 in Yang and Majda
(2018) and Fig. 8 here, their favorability conditions for convection are opposite with a clear east-west contrast. For 2-day waves, low-level negative potential temperature anomalies are induced at the leading edge of the convective envelope only when the mesoscale disturbances propagate at tilt angles of $315^{\circ} \leq \gamma<0^{\circ}$ and $0^{\circ} \leq \gamma<45^{\circ}$, providing favorable conditions for convection. In contrast, for CCKWs, these occurs only when mesoscale disturbances propagate at tilt angles of $135^{\circ} \leq \gamma<225^{\circ}$. For both 2 -day waves and CCKWs, the northward-propagating $\left(45^{\circ} \leq \gamma<135^{\circ}\right)$ and southwardpropagating $\left(225^{\circ} \leq \gamma<315^{\circ}\right)$ mesoscale disturbances 

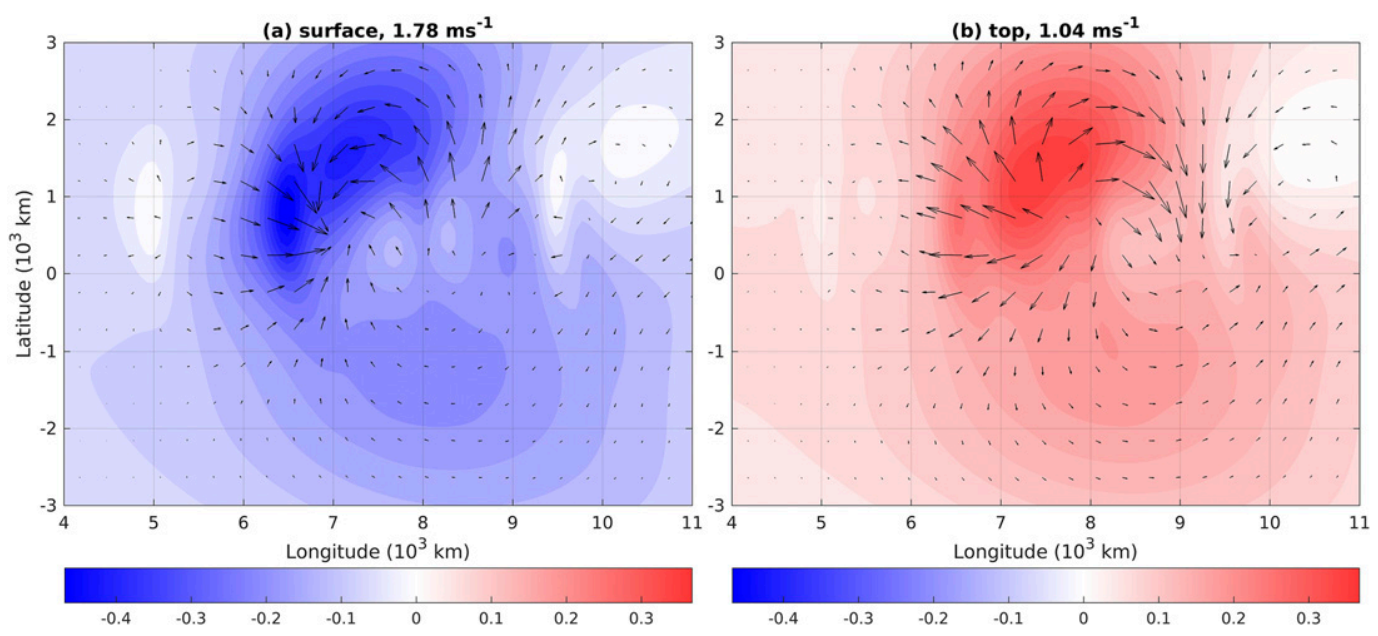

FIG. 14. As in Fig. 7, but driven by meridionally asymmetric mean heating.

tend to suppress convection in one hemisphere and trigger convection in the other, introducing meridional asymmetry. In the fast propagation scenario, eddy transfer of temperature with low-level positive anomalies dominates, providing unfavorable conditions for convection.

Table 4 compares the upscale impact of mesoscale disturbances on symmetric 2-day waves and CCKWs in terms of midtropospheric winds and pressure perturbation at a height of $5.24 \mathrm{~km}$. For 2-day waves, mesoscale disturbances propagating at tilt angles of $315^{\circ} \leq \gamma<0^{\circ}$ and $0^{\circ} \leq \gamma<45^{\circ}$ induce westerlies, strengthening the inflow to 2-day waves from west to east. Such strengthening also occurs for CCKWs as mesoscale disturbances propagating at tilt angles of $135^{\circ} \leq \gamma<225^{\circ}$. In contrast, weakening inflow scenarios occur at tilt angles of $135^{\circ} \leq \gamma<225^{\circ}$ for 2-day waves and $315^{\circ} \leq \gamma<0^{\circ}$ and $0^{\circ} \leq \gamma<45^{\circ}$ for CCKWs. For 2-day waves, both northeastward- and southeastward-propagating mesoscale disturbances induce jets accompanied by cyclonic flows, while northwestward- and southwestward-propagating mesoscale disturbances tend to induce jets accompanied by anticyclonic flow. In contrast, for CCKWs, those cyclonic flows do not occur. As far as tropical cyclogenesis is concerned, cyclonic flow is induced in the $\mathrm{SH}(\mathrm{NH})$ as mesoscale disturbances propagate at tilt angles of $45^{\circ} \leq \gamma<90^{\circ}\left(270^{\circ} \leq \gamma<315^{\circ}\right)$ in 2 -day waves. For CCKWs, negative pressure perturbation is induced at the leading edge of CCKWs, as mesoscale disturbances propagate at tilt angles of $135^{\circ} \leq \gamma<225^{\circ}$, that is, favorable conditions for tropical cyclogenesis.

Table 5 describes the upscale impact of mesoscale disturbances that propagate at various tilt angles on asymmetric 2-day waves. As far as favorability conditions for convection is concerned, favorable conditions occur only when mesoscale disturbances propagate at tilt angles of $0^{\circ} \leq \gamma<90^{\circ}$, exhibiting major meridional asymmetry. As a counterpart, the upscale impact of mesoscale disturbances that propagate at tilt angles of $270^{\circ} \leq \gamma<360^{\circ}$ suppresses convection near the equator and furthermore triggers shallow congestus convection in the $\mathrm{NH}$ at tilt angles of $315^{\circ} \leq \gamma<360^{\circ}$. The cases with the remaining tilt angles have unfavorable conditions for convection. As for the morphology of circulation, strengthening westerly inflow is induced only when mesoscale disturbances propagate at tilt angles of $0^{\circ} \leq \gamma<45^{\circ}$. The cases with tilt angles of $45^{\circ} \leq \gamma<180^{\circ}$ are characterized by northeastward/northwestward jets accompanied by anticyclonic flows and positive pressure perturbation in the $\mathrm{NH}$, while those with tilt angles of $180^{\circ} \leq \gamma<315^{\circ}$ have southwestward/southeastward jets accompanied by positive pressure perturbation. In the cases with tilt angles of $315^{\circ} \leq \gamma<360^{\circ}$, both cyclonic flows and negative pressure perturbation are induced along with east-southward jets in the $\mathrm{NH}$, thereby preconditioning tropical cyclogenesis. Such a scenario with favorable conditions for tropical cyclogenesis resulting from the upscale impact of mesoscale disturbances is distinguished from symmetric 2-day waves and CCKWs, highlighting the unique multiscale features of asymmetric 2-day waves.

\section{Concluding discussion}

As major components of synoptic variability of tropical convection, 2-day waves typically propagate westward in the form of superclusters, containing embedded mesoscale disturbances moving at various tilt angles. It is crucial to understand the multiscale interactions of tropical convection across the mesoscale and synoptic 

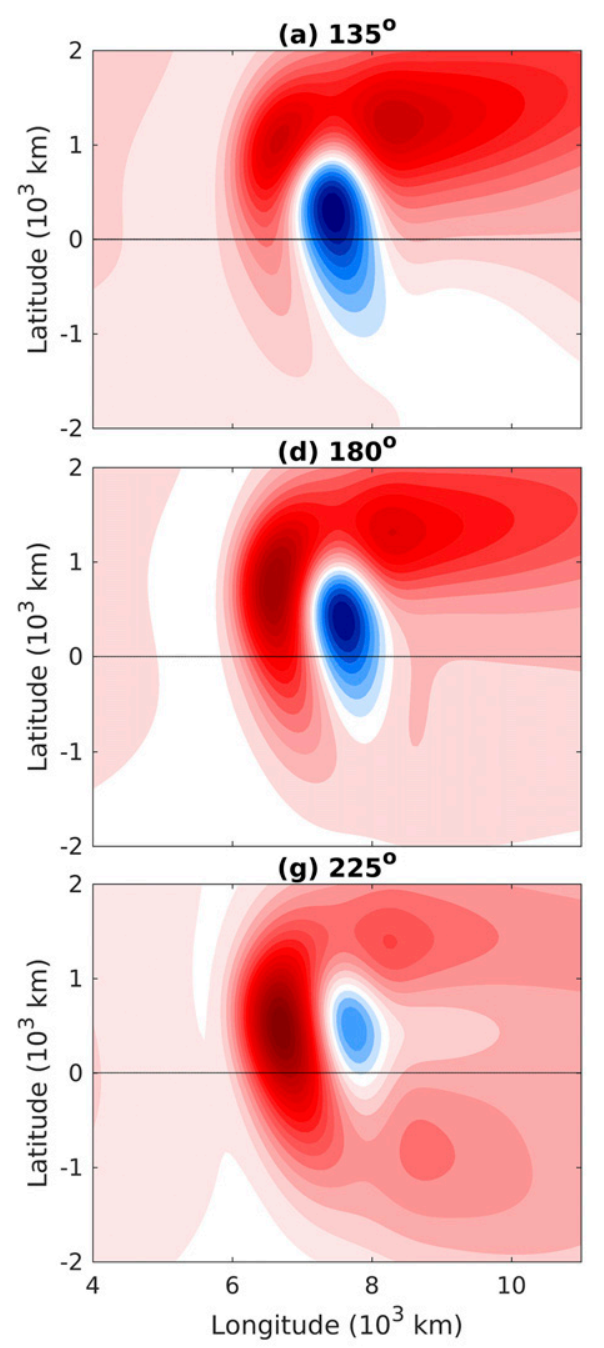

(b) $90^{\circ}$

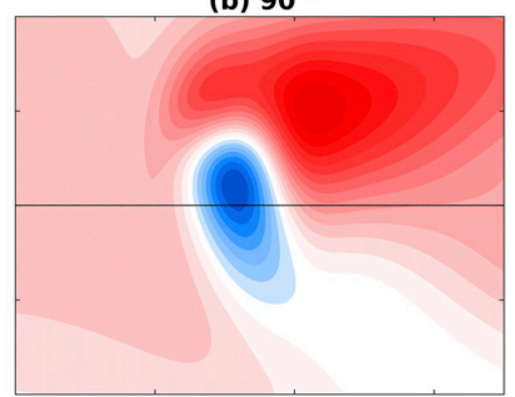

(e)

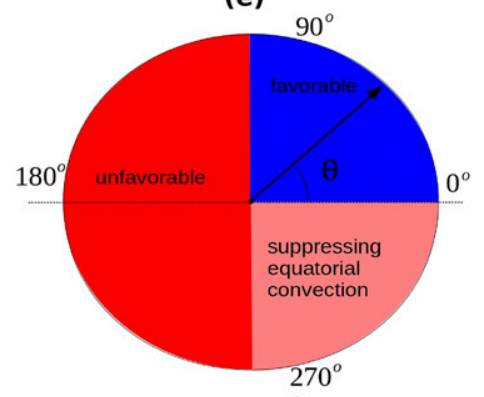

(h) $270^{\circ}$

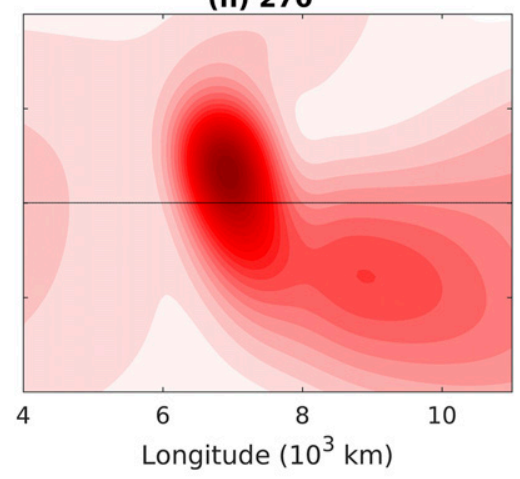

(c) $45^{\circ}$

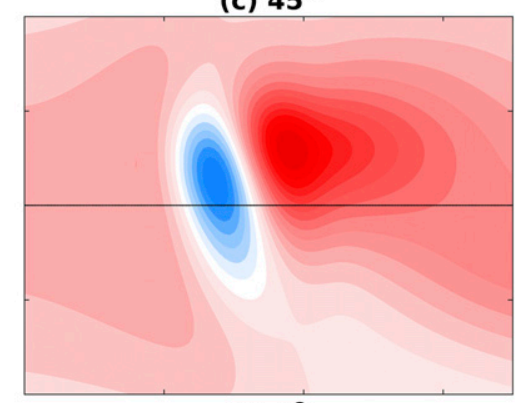

(f) $0^{\circ}$

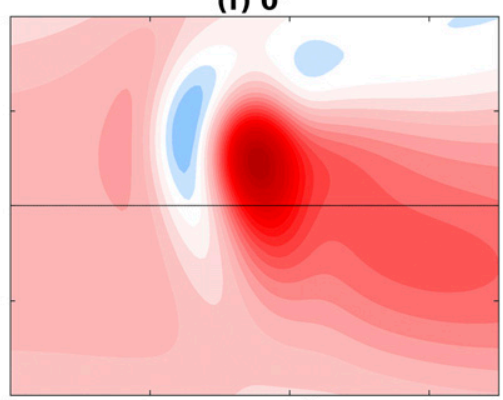

(h) $315^{\circ}$

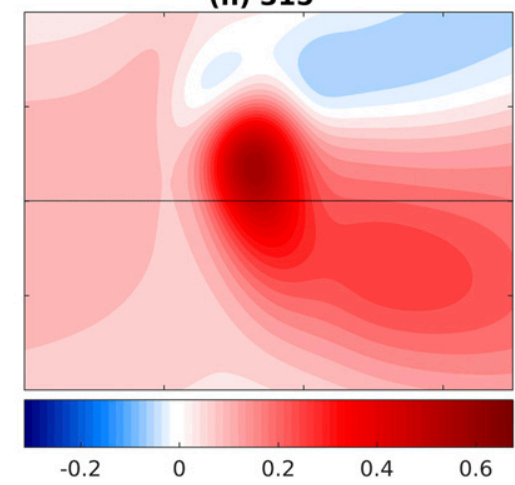

FIG. 15. As in Fig. 8, but driven by eddy terms modulated by a meridional asymmetric envelope. (e) Summary of favorability of convection in different tilt-angle cases (blue: favorable; pink: suppressing equatorial convection; red: unfavorable).

scale associated with 2-day waves. The goals of this paper include the following four aspects: first, using a simple multiscale framework to model the synopticscale 2-day waves with embedded mesoscale disturbances; second, assessing the upscale impact of those mesoscale disturbances that propagate at various tilt angles on 2-day waves in terms of favorability conditions for convection, characteristic morphology of circulation, and tropical cyclogenesis; third, investigating the upscale impact of mesoscale disturbances on asymmetric 2-day waves that propagate off the equator in the $\mathrm{NH}$; and last, comparing different theoretical predictions of the upscale impact of mesoscale disturbances on westward-propagating 2-day waves versus eastward-propagating CCKWs.

We addressed major aspects using the MESD model, originally derived by Majda (2007), to simulate 2-day waves as a synoptic-scale circulation response to mean heating and eddy transfer of momentum and temperature. The latter is generated by mesoscale fluctuations of flow fields associated with mesoscale tropical convective disturbances. The mean heating-driven synoptic-scale circulation response successfully captures several realistic features of 2-day waves, including surface-level (top level) wind convergence (divergence) in a front-torear tilt, while the circulation response to eddy transfer of momentum and temperature induces winds and potential temperature anomalies of comparable magnitude. The successful applications of the MESD model to simulate 2-day waves here and CCKWs in Yang and Majda (2018) further validate its appropriateness for modeling cluster-supercluster interactions across the mesoscale and synoptic scales. Therefore, it is promising to use the MESD model for simulating other convectively coupled equatorial waves, such as easterly 

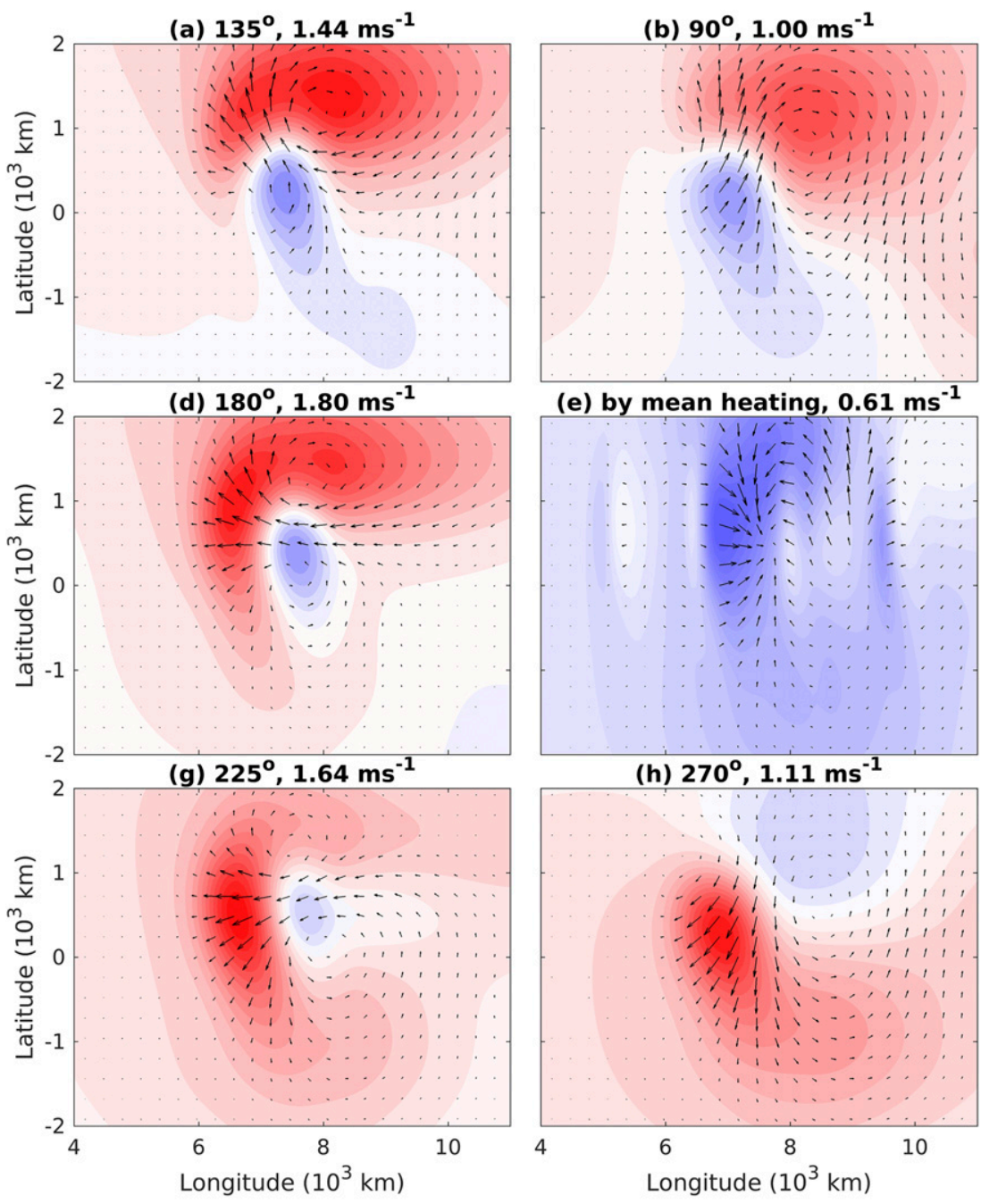

(b) $90^{\circ}, 1.00 \mathrm{~ms}^{-1}$

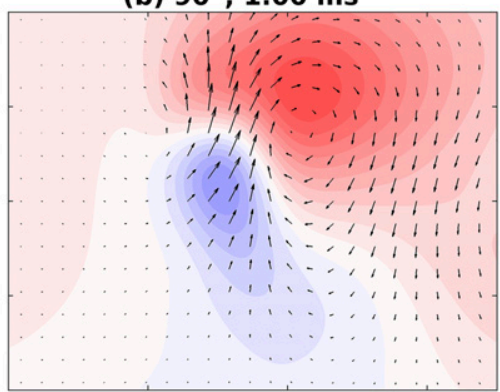

(e) by mean heating, $0.61 \mathrm{~ms}^{-1}$

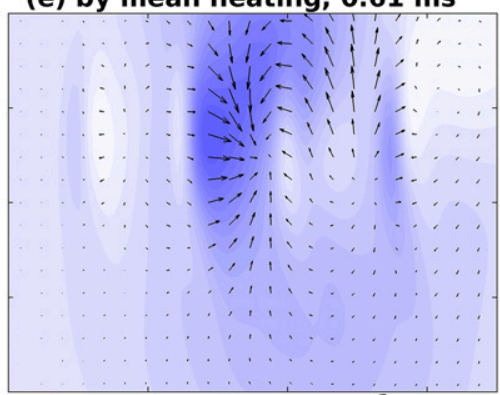

(c) $45^{\circ}, 1.38 \mathrm{~ms}^{-1}$

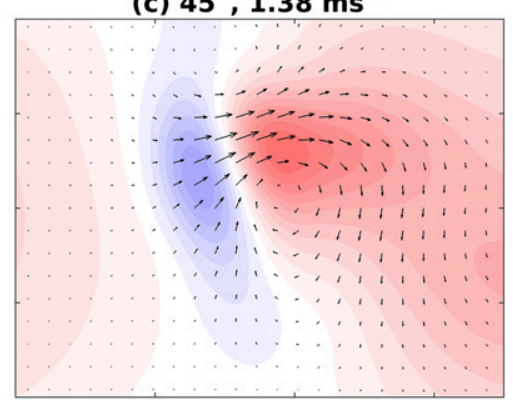

(f) $0^{\circ}, 1.47 \mathrm{~ms}^{-1}$

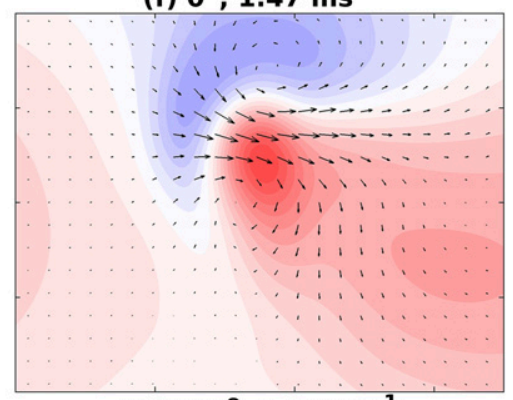

(h) $315^{\circ}, 1.05 \mathrm{~ms}^{-1}$

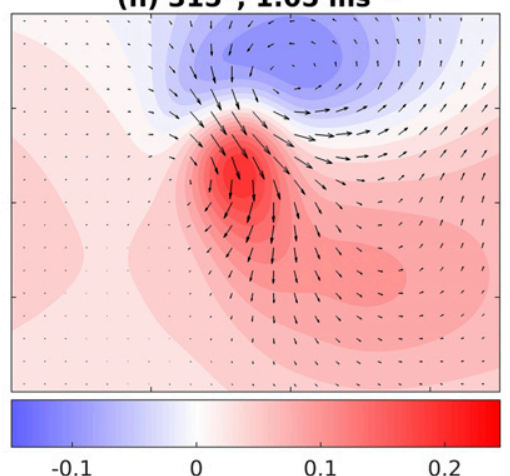

FIG. 16. As in Fig. 11, but in the middle troposphere $(5.24 \mathrm{~km})$ in the meridionally asymmetric case.

waves, that are prevalent in the ITCZ regions (Yang et al. 2003; Serra et al. 2008; Toma and Webster 2010a,b).

As inspired by the fact that MCSs are observed to propagate at various directions in the tropics, the upscale impact of mesoscale disturbances propagating at different tilt angles on mean heating-driven circulation response is considered. In particular, in the cases with tilt angles of $315^{\circ}-360^{\circ}$ and $0^{\circ}-45^{\circ}$, low-level negative potential temperature anomalies at a height of $2.62 \mathrm{~km}$ are induced to the west, triggering shallow congestus convection at the leading edge of the westwardpropagating envelope in a moist environment. Meanwhile, westerly inflow of a comparable magnitude is induced at the lower troposphere at a height of $5.24 \mathrm{~km}$, feeding additional moisture to the system as the convective envelope propagates westward. All these favorable conditions for convection as a result of the upscale impact of mesoscale disturbances identify a new mechanism for favoring of westward inertia-gravity waves over eastward inertia-gravity waves. However, the upscale impact also induces midtropospheric warm potential temperature anomalies to the west, which would suppress deep convection by increasing the saturation rate of vapor and decreasing CAPE. Such competing effects between triggering shallow convection at the lower troposphere and suppressing deep convection at the middle troposphere may be the reason why both eastward- and westward-propagating MCSs are observed inside the convective envelope of 2-day waves (Chen et al. 1996). A comparison of the upscale impact of mesoscale disturbances on symmetric 2-day waves and CCKWs shows that favorability for convection, morphology of circulation, and tropical cyclogenesis at various tilt angles are opposite of each other simply because their convective envelopes propagate in the opposite direction. These consistent results highlight a general feature of the 
TABLE 3. Comparison of upscale impact of mesoscale disturbances on symmetric 2-day waves and CCKWs in terms of favorability for convection. Favorable (highlighted in boldface text in the table) means that the upscale impact induces low-level (2.62 km) negative potential temperature anomalies in the leading edge, providing favorable conditions for convection and promoting forward propagation of synoptic-scale convective envelope, while unfavorable has the opposite meaning. Here symmetric 2-day waves refer to westwardpropagating 2-day waves with their maximum convection at the equator.

\begin{tabular}{|c|c|c|c|}
\hline $\begin{array}{l}\text { Propagating speed of } \\
\text { mesoscale disturbances }\end{array}$ & $\gamma$ & Symmetric 2-day wave & CCKW \\
\hline \multirow[t]{4}{*}{ Slow $\left(s<12 \mathrm{~m} \mathrm{~s}^{-1}\right)$} & $315^{\circ} \leq \gamma<360^{\circ}, 0^{\circ} \leq \gamma<45^{\circ}$ & Favorable & Unfavorable \\
\hline & $45^{\circ} \leq \gamma<135^{\circ}$ & $\begin{array}{l}\text { Suppressing (triggering) convection } \\
\text { to the north (south) }\end{array}$ & $\begin{array}{l}\text { Suppressing convection } \\
\text { to the north }\end{array}$ \\
\hline & $135^{\circ} \leq \gamma<225^{\circ}$ & Unfavorable & Favorable \\
\hline & $225^{\circ} \leq \gamma<315^{\circ}$ & $\begin{array}{l}\text { Suppressing (triggering) convection } \\
\text { to the south (north) }\end{array}$ & $\begin{array}{l}\text { Suppressing convection } \\
\text { to the south }\end{array}$ \\
\hline Fast $\left(s \geq 12 \mathrm{~m} \mathrm{~s}^{-1}\right)$ & All & Unfavorable & Unfavorable \\
\hline
\end{tabular}

upscale impact of mesoscale disturbances; that is, lowlevel negative potential temperature anomalies and inflow will always be induced in the direction from where the mesoscale disturbances propagate, triggering shallow congestus convection and advancing the synoptic-scale convective envelope.

Concerning the asymmetric 2-day waves propagating along the ITCZ in the $\mathrm{NH}$, the corresponding upscale impact of mesoscale disturbances exhibit distinct behavior at various tilt angles. Besides "favorable" and "unfavorable" regimes for the westward propagation of convective envelope, an extra regime with tilt angles of $270^{\circ}-360^{\circ}$ occurs in the $\mathrm{NH}$ by suppressing equatorial convection and triggering shallow congestus convection. This provides a mechanism to maintain the northward displacement of 2-day waves off the equator. Furthermore in the $\mathrm{NH}$, in the cases with tilt angles between $315^{\circ}$ and $360^{\circ}$, both cyclonic flows and negative pressure perturbation at low troposphere are induced, thereby preconditioning tropical cyclogenesis. This is a new mechanism to explain the prevalent tropical cyclogenesis in the subtropical regions, such as the ITCZ region over the northern WP. This is in addition to mechanisms involving the vertically sheared horizontal flows (Majda et al. 2008) and the effects of mesoscale vertical shear and moist microscale hot towers on vortex amplification (Majda et al. 2010).

Eddy transfer of momentum is also referred to as convective momentum transport (CMT) in tropical meteorology. Its significant role in driving large-scale circulation is confirmed through momentum budget analysis based on objectively analyzed sounding taken during the TOGA COARE intense observing period (Tung and Yanai 2002a,b). Khouider and Han (2013) shows evidence of energy exchange through momentum transport between small-scale circulation resulting from mesoscale convection and the propagating synopticscale wave based on cloud-resolving Weather Research and Forecasting (WRF) Model simulations. Moncrieff et al. (2017) introduced the multiscale coherent structure parameterization with a single baroclinic mode for CMT and added it into GCMs to represent the missing effects of organized tropical convection. The explicit expressions of eddy transfer of

TABLE 4. Comparison of upscale impact of mesoscale disturbances on symmetric 2-day waves and CCKWs in terms of low-level winds and pressure perturbation at a height of $5.24 \mathrm{~km}$. The propagation speed of mesoscale disturbances is fixed at $5 \mathrm{~m} \mathrm{~s}^{-1}$. Cyclonic flows and negative pressure perturbation are regarded as favorable conditions to precondition tropical cyclogenesis. Boldface text highlights strengthening inflow.

\begin{tabular}{|c|c|c|}
\hline$\gamma$ & Symmetric 2-day wave & CCKW \\
\hline $315^{\circ} \leq \gamma<360^{\circ}, 0^{\circ} \leq \gamma<45^{\circ}$ & Strengthening westerly inflow & Weakening easterly inflow \\
\hline $45^{\circ} \leq \gamma<90^{\circ}$ & $\begin{array}{l}\text { Inducing northeastward jets Accompanied by } \\
\text { cyclonic flow to the right }\end{array}$ & Inducing westerly winds to the north \\
\hline $90^{\circ} \leq \gamma<135^{\circ}$ & $\begin{array}{l}\text { Inducing northwestward jets accompanied by } \\
\text { anticyclonic flow to the right }\end{array}$ & $\begin{array}{l}\text { Inducing northwestward jets accompanied by } \\
\text { anticyclonic flows on both sides }\end{array}$ \\
\hline $135^{\circ} \leq \gamma<225^{\circ}$ & Weakening westerly inflow & Strengthening easterly inflow \\
\hline $225^{\circ} \leq \gamma<270^{\circ}$ & $\begin{array}{l}\text { Inducing southwestward jets accompanied by } \\
\text { anticyclonic flow to the left }\end{array}$ & $\begin{array}{l}\text { Inducing southwestward jets accompanied by } \\
\text { anticyclonic flows on both sides }\end{array}$ \\
\hline $270^{\circ} \leq \gamma<315^{\circ}$ & $\begin{array}{l}\text { Inducing southeastward jets accompanied by } \\
\text { cyclonic flow to the left }\end{array}$ & Inducing westerly winds to the south \\
\hline Tropical cyclogenesis & $\begin{array}{l}\text { By cyclonic flow: } 45^{\circ} \leq \gamma<90^{\circ} \text { in the } \mathrm{SH} \text { and } \\
270^{\circ} \leq \gamma<315^{\circ} \text { in the } \mathrm{NH}\end{array}$ & $\begin{array}{l}\text { By negative pressure: } 135^{\circ} \leq \gamma<225^{\circ} \text { at the } \\
\text { leading edge }\end{array}$ \\
\hline
\end{tabular}


TABLE 5. Upscale impact of mesoscale disturbances on asymmetric 2-day waves in terms of favorability for convection, morphology of circulation, and tropical cyclogenesis. Favorable preconditioning corresponds to the scenario with cyclonic flows and negative pressure perturbation in the NH that precondition tropical cyclogenesis, while suppressing has the opposite meaning. Neutral corresponds to the scenario with neither preconditioning nor suppressing conditions for tropical cyclogenesis. Here, asymmetric 2-day waves refer to westwardpropagating 2-day waves with their maximum convection in the $\mathrm{NH}$. Boldface text highlights favorable and/or strengthening conditions.

\begin{tabular}{|c|c|c|c|}
\hline \multicolumn{4}{|c|}{ Asymmetric 2-day wave } \\
\hline$\gamma$ & Favorability for convection & Morphology of circulation & $\begin{array}{c}\text { Tropical } \\
\text { cyclogenesis }\end{array}$ \\
\hline $0^{\circ} \leq \gamma<45^{\circ}$ & Favorable & $\begin{array}{l}\text { Strengthening westerly inflow and inducing } \\
\text { clockwise flows and positive pressure } \\
\text { perturbation at the equator }\end{array}$ & Neutral \\
\hline $45^{\circ} \leq \gamma<90^{\circ}$ & Favorable & $\begin{array}{l}\text { Inducing northeastward jets accompanied } \\
\text { by anticyclonic flows and positive } \\
\text { pressure perturbation in the NH }\end{array}$ & Suppressing \\
\hline $90^{\circ} \leq \gamma<180^{\circ}$ & Unfavorable & $\begin{array}{l}\text { Inducing northwestward jets accompanied } \\
\text { by anticyclonic flow and positive pressure } \\
\text { perturbation in the NH }\end{array}$ & Suppressing \\
\hline $180^{\circ} \leq \gamma<270^{\circ}$ & Unfavorable & $\begin{array}{l}\text { Inducing southwestward jets accompanied } \\
\text { by positive pressure perturbation at the } \\
\text { equator }\end{array}$ & Neutral \\
\hline $270^{\circ} \leq \gamma<315^{\circ}$ & Suppressing equatorial convection & $\begin{array}{l}\text { Inducing southeastward jets accompanied } \\
\text { by positive pressure perturbation at the } \\
\text { equator }\end{array}$ & Neutral \\
\hline $315^{\circ} \leq \gamma<360^{\circ}$ & $\begin{array}{l}\text { Suppressing equatorial convection, } \\
\text { preconditioning shallow congestus } \\
\text { convection in the } \mathrm{NH}\end{array}$ & $\begin{array}{l}\text { Inducing southeastward jets with cyclonic } \\
\text { flows and negative pressure perturbation } \\
\text { in the NH }\end{array}$ & $\begin{array}{l}\text { Favorable } \\
\text { preconditioning }\end{array}$ \\
\hline
\end{tabular}

momentum and temperature from the MESD model in Table 2 provide a dynamically based strategy to improve this parameterization. According to the MESD model, eddy transfer of temperature also arises simultaneously along with eddy transfer of momentum in the synopticscale equations in Eqs. (1a)-(1e), and it becomes dominant for the fast-propagating regime of mesoscale disturbances (Yang and Majda 2018). The importance of eddy transfer of temperature in both observational studies and the parameterization of organized tropical convection is currently underestimated and thus requires further investigation.

The MESD model under the current configuration can be elaborated and generalized in various ways. Instead of prescribing the two-scale heating, it should be promising to couple the MESD model with some active heating function for the cloud life cycle, such as the multicloud models (Khouider and Majda 2006c,a,b, 2008a,b; Khouider et al. 2010, 2011). Also, the MESD model emphasizes the upscale impact of mesoscale disturbances from the mesoscale to the synoptic scale, but the modulation effects of synoptic-scale circulation on mesoscale heating are neglected. A full consideration of two-way feedback may provide more realistic 2-day waves, extending the power of the MESD model by capturing feedbacks across scales. It would be interesting to exploit the advances in the wave-mean flow interaction as introduced by Andrews and McIntyre (1976a,b, 1978a,b,c). Finally, the MESD model could also be used as a framework to diagnostically analyze multiscale interactions of tropical convection in observational and reanalysis data.

Acknowledgments. This research of A. J. M. is partially supported by the Office of Naval Research Grant ONR MURI N00014-12-1-0912 and the Center for Prototype Climate Modeling (CPCM) of New York University Abu Dhabi (NYUAD) Research Institute. Q. Y. is funded as a postdoctoral fellow by CPCM in NYUAD Research Institute.

\section{REFERENCES}

Andrews, D. G., and M. E. McIntyre, 1976a: Planetary waves in horizontal and vertical shear: Asymptotic theory for equatorial waves in weak shear. J. Atmos. Sci., 33, 2049-2053, https:// doi.org/10.1175/1520-0469(1976)033<2049:PWIHAV>2.0.CO;2.

$\longrightarrow$, and $-1976 \mathrm{~b}$ : Planetary waves in horizontal and vertical shear: The generalized Eliassen-Palm relation and the mean zonal acceleration. J. Atmos. Sci., 33, 2031-2048, https://doi.org/ 10.1175/1520-0469(1976)033<2031:PWIHAV>2.0.CO;2.

— Drazin theorems for waves on axismmetric mean flows in compressible atmospheres. J. Atmos. Sci., 35, 175-185, https:// doi.org/10.1175/1520-0469(1978)035<0175:GEPACD>2.0.CO;2. , and - 1978b: An exact theory of nonlinear waves on a Lagrangian-mean flow. J. Fluid Mech., 89, 609-646, https://doi.org/ 10.1017/S0022112078002773. 
, and $-1978 \mathrm{c}:$ On wave-action and its relatives. J. Fluid Mech., 89, 647-664, https://doi.org/10.1017/S0022112078002785.

— , J. R. Holton, and C. B. Leovy, 1987: Middle Atmosphere Dynamics. International Geophysics Series, Vol. 40, Academic Press, 489 pp.

Biello, J. A., and A. J. Majda, 2005: A new multiscale model for the Madden-Julian oscillation. J. Atmos. Sci., 62, 1694-1721, https://doi.org/10.1175/JAS3455.1.

$\longrightarrow$, and - 2006: Modulating synoptic scale convective activity and boundary layer dissipation in the IPESD models of the Madden-Julian oscillation. Dyn. Atmos. Oceans, 42, 152-215, https://doi.org/10.1016/j.dynatmoce.2005.10.005.

$\longrightarrow$, and — 2010: Intraseasonal multi-scale moist dynamics of the tropical atmosphere. Commun. Math. Sci., 8, 519-540, https://doi.org/10.4310/CMS.2010.v8.n2.a11.

Chen, S. S., and R. A. Houze, 1997: Diurnal variation and life-cycle of deep convective systems over the tropical Pacific warm pool. Quart. J. Roy. Meteor. Soc., 123, 357-388, https://doi.org/ 10.1002/qj.49712353806.

— , R. A. Houze Jr., and B. E. Mapes, 1996: Multiscale variability of deep convection in relation to large-scale circulation in TOGA COARE. J. Atmos. Sci., 53, 1380-1409, https://doi.org/ 10.1175/1520-0469(1996)053<1380:MVODCI > 2.0.CO;2.

Clayson, C. A., B. Strahl, and J. Schrage, 2002: 2-3-day convective variability in the tropical western Pacific. Mon. Wea. Rev., 130, 529-548, https://doi.org/10.1175/1520-0493(2002)130<0529: DCVITT $>2.0 . \mathrm{CO} ; 2$.

Crook, N. A., and M. W. Moncrieff, 1988: The effect of large-scale convergence on the generation and maintenance of deep moist convection. J. Atmos. Sci., 45, 3606-3624, https://doi.org/ 10.1175/1520-0469(1988)045<3606:TEOLSC > 2.0.CO;2.

Dai, A., 2006: Precipitation characteristics in eighteen coupled climate models. J. Climate, 19, 4605-4630, https://doi.org/ 10.1175/JCLI3884.1.

Dunkerton, T. J., M. Montgomery, and Z. Wang, 2009: Tropical cyclogenesis in a tropical wave critical layer: Easterly waves. Atmos. Chem. Phys., 9, 5587-5646, https://doi.org/10.5194/ acp-9-5587-2009.

Frank, W. M., and P. E. Roundy, 2006: The role of tropical waves in tropical cyclogenesis. Mon. Wea. Rev., 134, 2397-2417, https:// doi.org/10.1175/MWR3204.1.

Grabowski, W. W., and M. W. Moncrieff, 2001: Large-scale organization of tropical convection in two-dimensional explicit numerical simulations. Quart. J. Roy. Meteor. Soc., 127, 445468, https://doi.org/10.1002/qj.49712757211.

Haertel, P. T., and R. H. Johnson, 1998: Two-day disturbances in the equatorial western Pacific. Quart. J. Roy. Meteor. Soc., 124, 615-636, https://doi.org/10.1002/qj.49712454611.

— , and G. N. Kiladis, 2004: Dynamics of 2-day equatorial waves. J. Atmos. Sci., 61, 2707-2721, https://doi.org/10.1175/ JAS3352.1.

,,-- A. Denno, and T. M. Rickenbach, 2008: Vertical-mode decompositions of 2-day waves and the Madden-Julian oscillation. J. Atmos. Sci., 65, 813-833, https://doi.org/10.1175/ 2007JAS2314.1.

Holton, J. R., 1973: An introduction to dynamic meteorology. Amer. J. Phys., 41, 752-754, https://doi.org/10.1119/1.1987371.

Houze, R. A., Jr., 1975: Squall lines observed in the vicinity of the researcher during phase III of GATE. Preprints, 16th Radar Meteorology Conf., Houston, TX, Amer. Meteor. Soc., 206-209. , 1977: Structure and dynamics of a tropical squall-line system. Mon. Wea. Rev., 105, 1540-1567, https://doi.org/10.1175/15200493(1977)105<1540:SADOAT>2.0.CO;2.
- 2004: Mesoscale convective systems. Rev. Geophys., 42, RG4003, https://doi.org/10.1029/2004RG000150.

Khouider, B., and A. J. Majda, 2006a: Model multi-cloud parameterizations for convectively coupled waves: Detailed nonlinear wave evolution. Dyn. Atmos. Oceans, 42, 59-80, https:// doi.org/10.1016/j.dynatmoce.2005.12.001.

$\longrightarrow$, and —, 2006b: Multicloud convective parametrizations with crude vertical structure. Theor. Comput. Fluid Dyn., 20, 351-375, https://doi.org/10.1007/s00162-006-0013-2.

$\longrightarrow$, and $-2006 \mathrm{c}$ : A simple multicloud parameterization for convectively coupled tropical waves. Part I: Linear analysis. J. Atmos. Sci., 63, 1308-1323, https://doi.org/10.1175/JAS3677.1.

$\longrightarrow$, and _ 2008a: Equatorial convectively coupled waves in a simple multicloud model. J. Atmos. Sci., 65, 3376-3397, https:// doi.org/10.1175/2008JAS2752.1.

$\longrightarrow$, and — 2008b: Multicloud models for organized tropical convection: Enhanced congestus heating. J. Atmos. Sci., 65, 895-914, https://doi.org/10.1175/2007JAS2408.1.

— , and Y. Han, 2013: Simulation of convectively coupled waves using WRF: A framework for assessing the effects of mesoscales on synoptic scales. Theor. Comput. Fluid Dyn., 27, 473489, https://doi.org/10.1007/s00162-012-0276-8.

_ J. Biello, and A. J. Majda, 2010: A stochastic multicloud model for tropical convection. Commun. Math. Sci., 8, 187216, https://doi.org/10.4310/CMS.2010.v8.n1.a10.

— A. St-Cyr, A. J. Majda, and J. Tribbia, 2011: The MJO and convectively coupled waves in a coarse-resolution GCM with a simple multicloud parameterization. J. Atmos. Sci., 68 , 240-264, https://doi.org/10.1175/2010JAS3443.1.

Kiladis, G. N., M. C. Wheeler, P. T. Haertel, K. H. Straub, and P. E. Roundy, 2009: Convectively coupled equatorial waves. Rev. Geophys., 47, RG2003, https://doi.org/10.1029/2008RG000266; Corrigendum, 49, RG3004, https://doi.org/10.1029/2011RG000370.

Li, G., and S.-P. Xie, 2014: Tropical biases in CMIP5 multimodel ensemble: The excessive equatorial Pacific cold tongue and double ITCZ problems. J. Climate, 27, 1765-1780, https://doi.org/ 10.1175/JCLI-D-13-00337.1.

Lin, J.-L., 2007: The double-ITCZ problem in IPCC AR4 coupled GCMS: Ocean-atmosphere feedback analysis. J. Climate, 20, 4497-4525, https://doi.org/10.1175/JCLI4272.1.

Lindzen, R. S., 1987: On the development of the theory of the QBO. Bull. Amer. Meteor. Soc., 68, 329-337, https://doi.org/ 10.1175/1520-0477(1987)068<0329:OTDOTT >2.0.CO;2.

Lussier, L. L., III, B. Rutherford, M. T. Montgomery, M. A. Boothe, and T. J. Dunkerton, 2015: Examining the roles of the easterly wave critical layer and vorticity accretion during the tropical cyclogenesis of hurricane sandy. Mon. Wea. Rev., 143, 1703-1722, https://doi.org/10.1175/MWR-D-14-00001.1.

Majda, A. J., 2007: New multiscale models and self-similarity in tropical convection. J. Atmos. Sci., 64, 1393-1404, https://doi.org/ 10.1175/JAS3880.1

— , and R. Klein, 2003: Systematic multiscale models for the tropics. J. Atmos. Sci., 60, 393-408, https://doi.org/10.1175/ 1520-0469(2003)060<0393:SMMFTT $>2.0 . \mathrm{CO} ; 2$.

— traseasonal oscillations. Proc. Natl. Acad. Sci. USA, 101, 47364741, https://doi.org/10.1073/pnas.0401034101.

, and Q. Yang, 2016: A multiscale model for the intraseasonal impact of the diurnal cycle over the Maritime Continent on the Madden-Julian oscillation. J. Atmos. Sci., 73, 579-604, https:// doi.org/10.1175/JAS-D-15-0158.1.

_, M. Mohammadian, and Y. Xing, 2008: Vertically sheared horizontal flow with mass sources: A canonical balanced 
model. Geophys. Astrophys. Fluid Dyn., 102, 543-591, https:// doi.org/10.1080/03091920802044787.

—, Y. Xing, and M. Mohammadian, 2010: Moist multi-scale models for the hurricane embryo. J. Fluid Mech., 657, 478-501, https://doi.org/10.1017/S0022112010001515.

Mapes, B. E., and R. A. Houze Jr., 1993: Cloud clusters and superclusters over the oceanic warm pool. Mon. Wea. Rev., 121, 1398-1416, https://doi.org/10.1175/1520-0493(1993)121<1398: CCASOT $>2.0 . \mathrm{CO} ; 2$.

- S. Tulich, J. Lin, and P. Zuidema, 2006: The mesoscale convection life cycle: Building block or prototype for large-scale tropical waves? Dyn. Atmos. Oceans, 42, 3-29, https://doi.org/ 10.1016/j.dynatmoce.2006.03.003.

Matsuno, T., 1966: Quasi-geostrophic motions in the equatorial area. J. Meteor. Soc. Japan, 44, 25-43, https://doi.org/10.2151/ jmsj1965.44.1_25.

Moncrieff, M., 1978: The dynamical structure of two-dimensional steady convection in constant vertical shear. Quart. J. Roy. Me teor. Soc., 104, 543-567, https://doi.org/10.1002/qj.49710444102.

_- 1981: A theory of organized steady convection and its transport properties. Quart. J. Roy. Meteor. Soc., 107, 29-50, https://doi.org/10.1002/qj.49710745103.

_ 1985: Steady convection in pressure coordinates. Quart. J. Roy. Meteor. Soc., 111, 857-866, https://doi.org/10.1002/ qj. 49711146911.

Moncrieff, M. W., 1992: Organized convective systems: Archetypal dynamical models, mass and momentum flux theory, and parametrization. Quart. J. Roy. Meteor. Soc., 118, 819-850, https://doi.org/10.1002/qj.49711850703.

— C. Liu, and P. Bogenschutz, 2017: Simulation, modeling, and dynamically based parameterization of organized tropical convection for global climate models. J. Atmos. Sci., 74, 13631380, https://doi.org/10.1175/JAS-D-16-0166.1.

Nakazawa, T., 1988: Tropical super clusters within intraseasonal variations over the western Pacific. J. Meteor. Soc. Japan, 66, 823-839, https://doi.org/10.2151/jmsj1965.66.6_823.

Plumb, R. A., and R. C. Bell, 1982: A model of the quasi-biennial oscillation on an equatorial beta-plane. Quart. J. Roy. Meteor. Soc., 108, 335-352, https://doi.org/10.1002/qj.49710845604.

Robert, A., 1982: Cloud clusters and large-scale vertical motions in the tropics. J. Meteor. Soc. Japan, 60, https://doi.org/10.2151/ jmsj1965.60.1_319.

Roundy, P. E., and W. M. Frank, 2004: A climatology of waves in the equatorial region. J. Atmos. Sci., 61, 2105-2132, https://doi.org/ 10.1175/1520-0469(2004)061<2105:ACOWIT>2.0.CO; .

Schrage, J. M., C. A. Clayson, and B. Strahl, 2001: Statistical properties of episodes of enhanced 2-3-day convection in the Indian and Pacific Oceans. J. Climate, 14, 3482-3494, https:// doi.org/10.1175/1520-0442(2001)014<3482:SPOEOE>2.0.CO;2.

Serra, Y. L., G. N. Kiladis, and M. F. Cronin, 2008: Horizontal and vertical structure of easterly waves in the Pacific ITCZ. J. Atmos. Sci., 65, 1266-1284, https://doi.org/10.1175/ 2007JAS2341.1.

Stechmann, S. N., and A. J. Majda, 2009: Gravity waves in shear and implications for organized convection. J. Atmos. Sci., 66, 2579-2599, https://doi.org/10.1175/2009JAS2976.1.

Straub, K. H., and G. N. Kiladis, 2002: Observations of a convectively coupled Kelvin wave in the eastern Pacific ITCZ. J. Atmos. Sci. 59, 30-53, https://doi.org/10.1175/1520-0469(2002)059<0030: $\mathrm{OOACCK}>2.0 . \mathrm{CO} ; 2$

Takahashi, M., and J. R. Holton, 1991: The mean zonal flow response to Rossby wave and gravity wave forcing in the equatoria lower stratosphere: Relationship to the QBO. J. Atmos. Sci., 48
2078-2088, https://doi.org/10.1175/1520-0469(1991)048<2078: TMZFRT $>2.0 . \mathrm{CO} ; 2$.

Takayabu, Y. N., 1994a: Large-scale cloud disturbances associated with equatorial waves. Part I: Spectral features of the cloud disturbances. J. Meteor. Soc. Japan, 72, 433-449.

1994b: Large-scale cloud disturbances associated with equatorial waves. Part II: Westward-propagating inertiogravity waves. J. Meteor. Soc. Japan, 72, 451-465, https://doi.org/ 10.2151/jmsj1965.72.3_451.

- K. Kau, and C. Sui, 1996: Observation of a quasi-2-day wave during TOGA COARE. Mon. Wea. Rev., 124, 1892-1913, https:// doi.org/10.1175/1520-0493(1996)124<1892:OOAQDW>2.0.CO;2.

Tao, W.-K., and M. W. Moncrieff, 2009: Multiscale cloud system modeling. Rev. Geophys., 47, RG4002, https://doi.org/10.1029/ 2008RG000276.

Tokay, A., and D. A. Short, 1996: Evidence from tropical raindrop spectra of the origin of rain from stratiform versus convective clouds. J. Appl. Meteor., 35, 355-371, https://doi.org/10.1175/ 1520-0450(1996)035<0355:EFTRSO > 2.0.CO;2.

Toma, V. E., and P. J. Webster, 2010a: Oscillations of the intertropical convergence zone and the genesis of easterly waves. Part I: Diagnostics and theory. Climate Dyn., 34, 587604, https://doi.org/10.1007/s00382-009-0584-x.

- and 2010b: Oscillations of the intertropical convergence zone and the genesis of easterly waves. Part II: Numerical verification. Climate Dyn., 34, 605-613, https://doi.org/ 10.1007/s00382-009-0585-9.

Tung, W.-W., and M. Yanai, 2002a: Convective momentum transport observed during the TOGA COARE IOP. Part I: General features. J. Atmos. Sci., 59, 1857-1871, https://doi.org/ 10.1175/1520-0469(2002)059<1857:CMTODT >2.0.CO;2.

- and $-2002 \mathrm{~b}$ : Convective momentum transport observed during the TOGA COARE IOP. Part II: Case studies. J. Atmos. Sci., 59, 2535-2549, https://doi.org/10.1175/15200469(2002)059<2535:CMTODT > 2.0.CO;2.

Wang, Z., M. Montgomery, and T. Dunkerton, 2010: Genesis of pre-Hurricane Felix (2007). Part I: The role of the easterly wave critical layer. J. Atmos. Sci., 67, 1711-1729, https://doi.org/ 10.1175/2009JAS3420.1.

Wheeler, M., and G. N. Kiladis, 1999: Convectively coupled equatorial waves: Analysis of clouds and temperature in the wavenumberfrequency domain. J. Atmos. Sci., 56, 374-399, https://doi.org/ 10.1175/1520-0469(1999)056<0374:CCEWAO > 2.0.CO;2.

- — , and P. J. Webster, 2000: Large-scale dynamical fields associated with convectively coupled equatorial waves. J. Atmos. Sci., 57, 613-640, https://doi.org/10.1175/15200469(2000)057<0613:LSDFAW >2.0.CO;2.

Woelfle, M., S. Yu, C. Bretherton, and M. Pritchard, 2018: Sensitivity of coupled tropical Pacific model biases to convective parameterization in CESM1. J. Adv. Model. Earth Syst., 10, 126-144, https://doi.org/10.1002/2017MS001176.

Yanai, M., and R. H. Johnson, 1993: Impacts of cumulus convection on thermodynamic fields. The Representation of Cumulus Convection in Numerical Models, Meteor. Monogr., No. 46, Amer. Meteor. Soc., 39-62.

Yang, Q., and A. J. Majda, 2014: A multi-scale model for the intraseasonal impact of the diurnal cycle of tropical convection. Theor. Comput. Fluid Dyn., 28, 605-633, https://doi.org/ 10.1007/s00162-014-0336-3.

, and - 2017: Upscale impact of mesoscale disturbances of tropical convection on synoptic-scale equatorial waves in twodimensional flows. J. Atmos. Sci., 74, 3099-3120, https://doi.org/ 10.1175/JAS-D-17-0068.1. 
, and - 2018: Upscale impact of mesoscale disturbances of tropical convection on convectively coupled Kelvin waves. J. Atmos. Sci., 75, 85-111, https://doi.org/10.1175/JAS-D-170178.1.

Yang, G.-Y., B. Hoskins, and J. Slingo, 2003: Convectively coupled equatorial waves: A new methodology for identifying wave structures in observational data. J. Atmos. Sci., 60, 1637-1654, https://doi.org/10.1175/1520-0469(2003)060<1637: CCEWAN $>2.0 . \mathrm{CO} ; 2$.

- — waves. Part I: Horizontal and vertical structures. J. Atmos. Sci., 64, 3406-3423, https://doi.org/10.1175/JAS4017.1.
,-- , and $-2007 \mathrm{~b}$ : Convectively coupled equatorial waves. Part II: Propagation characteristics. J. Atmos. Sci., 64, 3424-3437, https://doi.org/10.1175/JAS4018.1.

,-- , and $-2007 \mathrm{c}$ : Convectively coupled equatorial waves. Part III: Synthesis structures and their forcing and evolution. J. Atmos. Sci., 64, 3438-3451, https://doi.org/10.1175/JAS4019.1.

Yang, Q., A. J. Majda, and B. Khouider, 2017: ITCZ breakdown and its upscale impact on the planetary-scale circulation over the eastern Pacific. J. Atmos. Sci., 74, 4023-4045, https://doi.org/ 10.1175/JAS-D-17-0021.1.

Zhang, C., 2005: Madden-Julian oscillation. Rev. Geophys., 43, RG2003, https://doi.org/10.1029/2004RG000158. 